\title{
A unified analysis of crustal motion in Southern California, 1970-2004: The SCEC crustal motion map
}

\author{
Z.-K. Shen, ${ }^{1,2}$ R. W. King, ${ }^{3}$ D. C. Agnew, ${ }^{4}$ M. Wang, ${ }^{1,5}$ T. A. Herring, ${ }^{3}$ D. Dong, ${ }^{6}$ \\ and P. Fang 4 \\ Received 27 May 2011; revised 4 August 2011; accepted 12 August 2011; published 5 November 2011.
}

[1] To determine crustal motions in and around southern California, we have processed and combined trilateration data collected from 1970 to 1992, VLBI data from 1979 to 1992, and GPS data from 1986 to 2004: a long temporal coverage required in part by the occurrence of several large earthquakes in this region. From a series of solutions for station positions, we have estimated interseismic velocities, coseismic displacements, and postseismic motions. Within the region from $31^{\circ} \mathrm{N}$ to $38^{\circ} \mathrm{N}$. and east to $114^{\circ} \mathrm{W}$, the final product includes estimated horizontal velocities for 1009 GPS, 190 trilateration, and 16 VLBI points, with ties between some of these used to stabilize the solution. All motions are relative to the Stable North American Reference Frame (SNARF) as realized through the velocities of 20 GPS stations. This provides a relatively dense set of horizontal velocity estimates, with well-tested errors, for the past quarter century over the plate boundary from $31^{\circ} \mathrm{N}$ to $36.5^{\circ} \mathrm{N}$. These velocities agree well with those from the Plate Boundary Observatory, which apply to a later time period. We also estimated vertical velocities, 533 of which have errors below $2 \mathrm{~mm} / \mathrm{yr}$. Most of these velocities are less than $1 \mathrm{~mm} / \mathrm{yr}$, but they show 2-4 mm/yr subsidence in the Ventura and Los Angeles basins and in the Salton Trough. Our analysis also included estimates of coseismic and postseismic motions related to the 1992 Landers, 1994 Northridge, 1999 Hector Mine, and 2003 San Simeon earthquakes. Postseismic motions increase logarithmically over time with a time constant of about 10 days, and generally mimic the direction and relative amplitude of the coseismic offsets.

Citation: Shen, Z.-K., R. W. King, D. C. Agnew, M. Wang, T. A. Herring, D. Dong, and P. Fang (2011), A unified analysis of crustal motion in Southern California, 1970-2004: The SCEC crustal motion map, J. Geophys. Res., 116, B11402, doi:10.1029/2011JB008549.

\section{Introduction}

[2] An important part of understanding the mechanics of plate boundaries is measuring the motions that take place along them. With the development of precise measurement techniques, especially the methods of space geodesy, and most notably the Global Positioning System (GPS), such measurements are being made across most plate boundaries that are not underwater. These data provide the best avail-

\footnotetext{
${ }^{1}$ Department of Earth and Space Sciences, University of California, Los Angeles, California, USA.

${ }^{2}$ School of Earth and Space Science, Peking University, Beijing, China.

${ }^{3}$ Department of Earth, Atmospheric and Planetary Sciences, Massachusetts Institute of Technology, Cambridge, Massachusetts, USA.

${ }^{4}$ Institute of Geophysics and Planetary Physics, Scripps Institution of Oceanography, University of California, San Diego, La Jolla, California, USA.

${ }^{5}$ Now at State Key Laboratory of Earthquake Dynamics, Institute of Geology, China Earthquake Administration, Beijing, China.

${ }^{6}$ Jet Propulsion Laboratory, California Institute of Technology, Pasadena, California, USA.

Copyright 2011 by the American Geophysical Union. 0148-0227/11/2011JB008549
}

able estimates of deformation over years and decades, which makes them crucial to our understanding of earthquake mechanics, and to estimating earthquake hazard.

[3] In California, tectonic deformation was first measured after the 1906 earthquake, though reliable estimates of deformation between earthquakes only began with trilateration measurements, which started about 1960 and were greatly expanded and improved after 1970. Space-geodetic measurements began with very long baseline interferometry (VLBI) experiments in 1979. Survey-mode GPS measurements for crustal deformation began in 1986, and expanded rapidly thereafter. Permanent GPS measurements began at about the same time, initially with a few tracking stations; a regional network of ten stations was in place by 1994 and grew rapidly thereafter, with over 250 stations by the end of the century.

[4] Subsets of these geodetic data have been used to study secular deformation [Savage, 1983; King and Savage, 1983, 1984; Savage et al., 1986; Minster and Jordan, 1987; Lisowski et al., 1991; Larson and Agnew, 1991; Larson and Webb, 1992; Larsen and Reilinger, 1992; Saucier and Humphreys, 1993; Donnellan et al., 1993; Shen and 
Jackson, 1993; Feigl et al., 1993; Savage and Lisowski, 1995a; Shen et al., 1996; Bennett et al., 1996; Bock et al., 1997; Savage and Lisowski, 1998; Walls et al., 1998; Argus et al., 1999; Wdowinski et al., 2001; Dixon et al., 2000; Gan et al., 2000; Miller et al., 2001; McClusky et al., 2001; Gonzalez-Garcia et al., 2003; Savage et al., 2004; Schmalzle et al., 2006; Plattner et al., 2007], coseismic deformations [Hudnut et al., 1994; Bennett et al., 1995; Hudnut et al., 1996; Bawden et al., 1997; Donnellan and Webb, 1998; Agnew et al., 2002; Rolandone et al., 2006], and postseismic deformation [Shen et al., 1994; Savage and Svarc, 1997; Donnellan and Lyzenga, 1998; Pollitz et al., 2000; Owen et al., 2002; Savage et al., 2003]. However, none of these analyses used all the data available, and some of the early GPS analyses have been superseded by improvements in GPS processing.

[5] The Southern California Earthquake Center (SCEC) has therefore supported the development of improved estimates of current earth motion, under the name of the Crustal Motion Model, or CMM (originally known as the Horizontal Deformation Velocity Map). The CMM is one of a number of SCEC community models, all of which aim to provide a consensus result for use by a wider community. The goal of the Crustal Motion Model is to combine precise geodetic data to estimate the motions of a large number of points in southern California. Version 1 of the CMM was released in October 1996, Version 2 in July 1998, and Version 3 in 2003. These versions have been used in a number of analyses [Jackson et al., 1995, 1997; Shen-Tu et al., 1999; Meade and Hager, 2005a, 2005b; Becker et al., 2005; Parsons, 2006; McCaffrey, 2005; Ward, 2007; Shen et al., 2007; Wdowinski et al., 2007]. These earlier versions did not include vertical motion, or treat postseismic motions adequately.

[6] This paper describes Version 4 of the CMM, which includes many GPS data not used before: both additional survey-mode data, and longer spans of data from permanent GPS sites. As in previous versions, the analysis also included precise trilateration data from the Crustal Strain project of the US Geological Survey (1970-1992) and VLBI data collected by the NASA Crustal Dynamics Program (1979-1992). The data analyzed end in mid-2004, just before the Parkfield earthquake in that year. Estimates of motion for the period since 2004 are produced routinely by several groups, notably the Plate Boundary Observatory (PBO: http://pboweb.unavco.org) and the NASA REASoN program (http://reason.scign.org). These more recent estimates contain data only from continuous GPS sites; this is appropriate because very few survey-mode GPS data have been collected since 2004 (Spinler et al. [2010] describes the one main exception). Although the PBO added substantially to the number of continuous GPS sites, the spatial density of these remains much less than the density of sites we have analyzed (Figure S1 of the auxiliary material). ${ }^{1}$ Our aim has been to make use of this denser but more heterogeneous network to give the best possible estimate of mo-

\footnotetext{
${ }^{1}$ Auxiliary material data sets are available at $\mathrm{ftp} / / \mathrm{ftp}$.agu.org/apend/jb/ $2011 \mathrm{jb} 008549$. Other auxiliary material files are in the HTML. doi:10.1029/2011JB008549.
}

tions over a long time period, as well as to describe the geodetic signals from the large earthquakes of the 1990's.

[7] We describe the procedures used to estimate velocities, discuss the decisions that were made in data selection and combination, explain the basis for the error estimates, and address some of the issues that have arisen. We have analyzed a wider range of data over a longer time span than have been used in most estimates of crustal motion. This longer time span has been needed in large part because several large earthquakes have occurred in the region of interest: the Landers earthquake $\left(\mathrm{M}_{w}\right.$ 7.3, June 28, 1992), the Northridge earthquake $\left(\mathrm{M}_{w} 6.7\right.$, January 17, 1994), and the Hector Mine earthquake $\left(\mathrm{M}_{w} 7.1\right.$, October 16, 1999). Allowing for the effects of these has significantly complicated the estimation of velocities, and has required us to address issues that arise only when processing a large and heterogeneous data set. The result, however, is a more rigorous representation than ever before of the crustal deformation field, one that includes secular velocities, coseismic displacements, and postseismic motion.

\section{Data Sets and Their Preparation}

[8] We first describe the different data we have used. Figure 1 shows the spatial coverage of each data type, and Figure 2 their temporal distribution.

\subsection{Trilateration Data}

[9] The first use of trilateration measurements to measure crustal motion was by the California Department of Water Resources (CDWR) [Hofmann, 1968]; their measurement program was continued by the California Division of Mines and Geology (CDMG). These measurements used a Geodimeter with refraction corrections made using endpoint and sometimes midpoint measurements [Savage, 1975; King et al., 1987]. Trilateration measurements were greatly expanded and improved by the US Geological Survey (USGS), who used a Geodolite with refraction corrections made from measurements made along the line of observation, giving an accuracy of about $10^{-7}$ [Savage and Prescott, 1973]. The USGS program began in 1970; the last measurements were collected after the Landers earthquake in 1992. Johnson et al. [1994] analyzed the southern California trilateration data to find the regional strain patterns. Comparisons of trilateration and GPS measurements, after correcting the trilateration data for a scale difference [Savage et al., 1996], generally show steady motion over the entire time span [Savage and Lisowski, 1995b; Anderson et al., 2003; Rolandone et al., 2008].

[10] Dong [1993] used the USGS measurements to estimate rates of change (and offsets as needed) for many trilateration lines, and used these rate data to estimate horizontal station velocities by imposing loose constraints on the rotation and translation of the network, a method that avoids any need to correct for the different scale factors. Section 3.5 describes how we combined this solution with the GPS and VLBI data.

\subsection{VLBI Data}

[11] High-quality measurements with VLBI began in 1979, with installations of the dual-frequency Mark III 
A. Trilateration
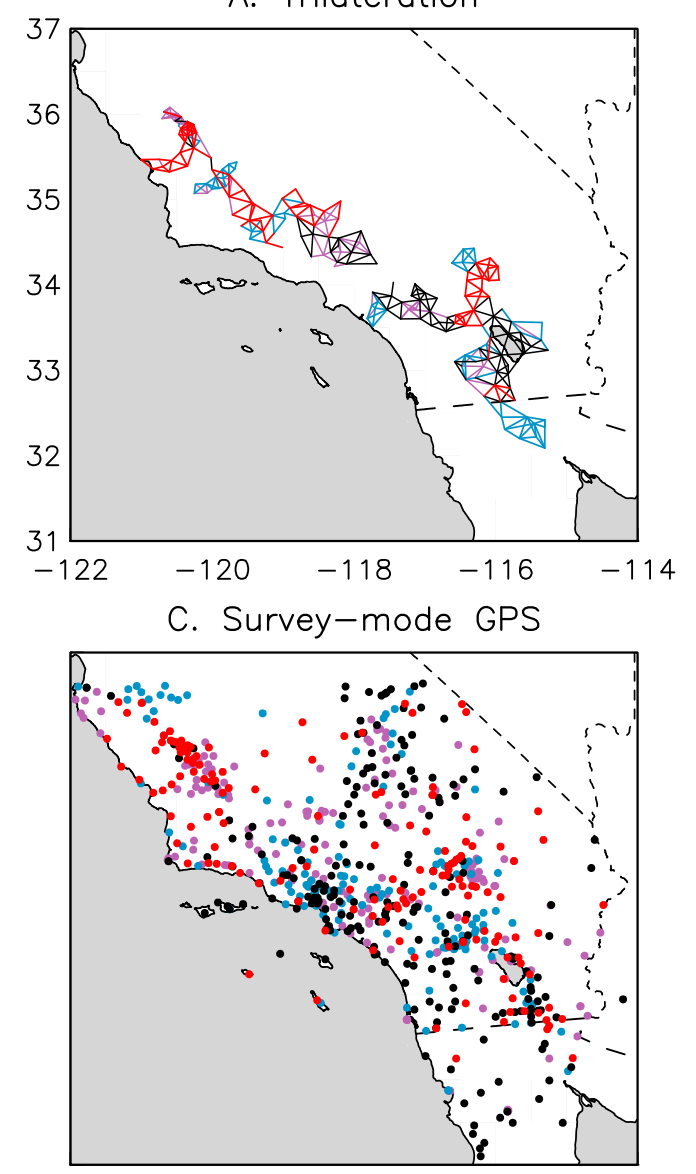

E. Time spans of Data Types

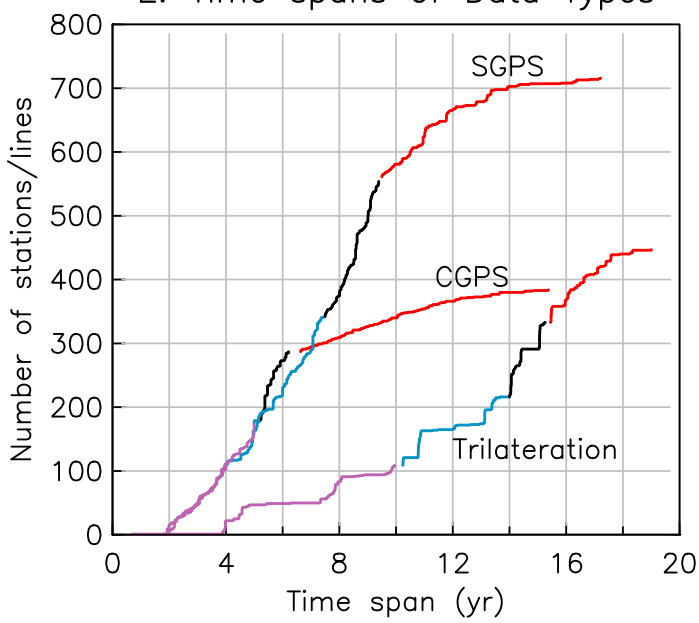

B. VLBI

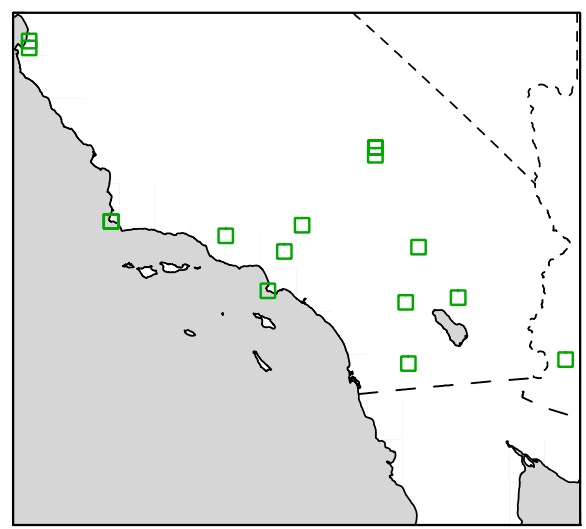

D. Continuous GPS

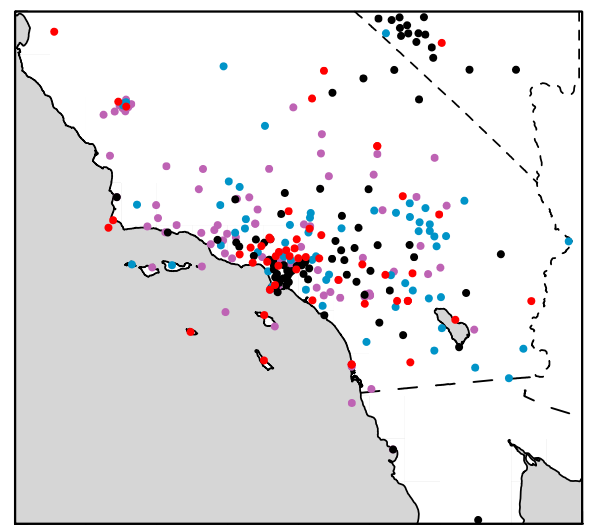

F. VLBI/Continuous GPS

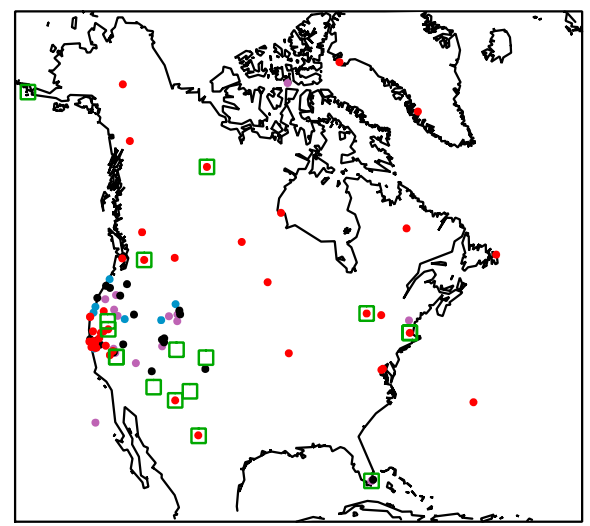

Figure 1. (a-d) The distribution in southern California of the four data types used in the CMM: for trilateration, the actual lines measured, and for GPS and VLBI the points occupied. All trilateration lines and GPS points are colored by the total time span covered for each one; the time spans are chosen to give nearly equal numbers in each class (quartiles). (e) The coloring applied to the cumulative distribution of time spans; the time spans for each quartile depend on the data type: for example, for survey-mode GPS (SGPS) one quarter of the points (shown in red) have time spans of 9 years or more. (f) The continuous GPS and VLBI stations outside of southern California; these were used to tie the reference frame to stable North America. 

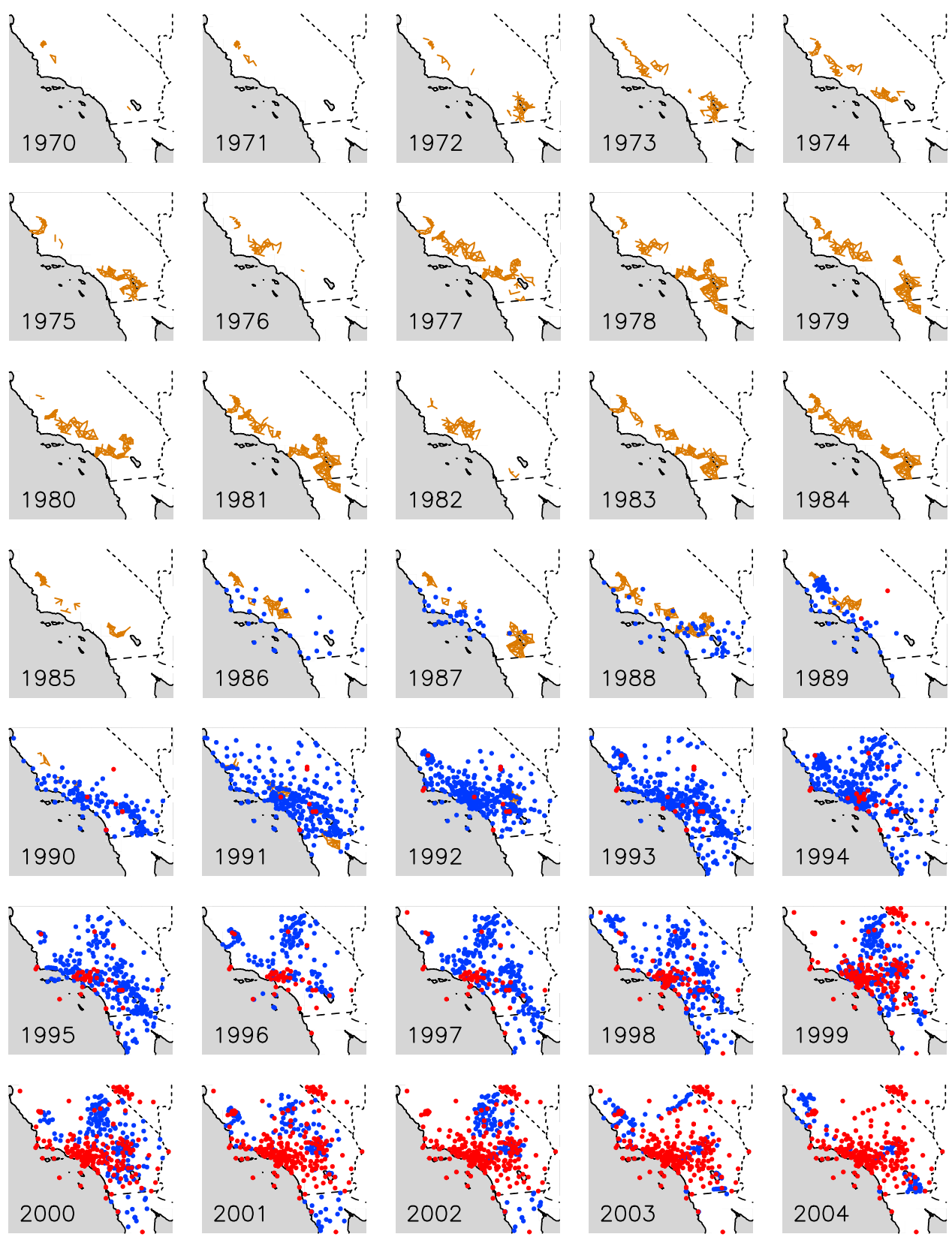

Figure 2. Locations of geodetic measurements used in the CMM solution, by year from 1970 through 2004. Trilateration lines are brown, survey-mode GPS points blue, and continuous GPS points red.

system as part of the NASA Crustal Dynamics Program. Southern California was one of the regional focus areas for this program, so relatively dense measurements were made. In the area shown in Figure 1, high-quality VLBI data were collected from four fixed radiotelescopes: three at the NASA Deep-Space Complex in the Mojave Desert, and one at Vandenberg Air Force Base. A pair of mobile systems [Davidson and Trask, 1985] observed roughly annually at ten sites [Gordon et al., 1993]. Data observed at some sites span more than 10 years, and the velocities have uncertainties of $1-2 \mathrm{~mm} / \mathrm{yr}$. While the VLBI stations were few, they capture the deformation field before the 1992 Landers earthquake.

\subsection{Survey-Mode GPS Data}

[12] Because testing of the GPS satellite constellation took place at the Yuma Proving Grounds, close to southern California, this region had relatively good coverage even during the early period of the system. The first precise measurements for crustal deformation were made in 1986 by the USGS, by the National Geodetic Survey (NGS), and by the Jet Propulsion Laboratory (JPL). A joint program of scientists from four universities [Feigl et al., 1993] made repeat measurements of about 30 sites between 1986 and 1992. Starting in 1988, NGS and university scientists [Bennett et al., 1996] made similar measurements in the Salton Trough and Riverside County. In 1991 the NGS and 
the California Department of Transportation made a statewide survey that was partly repeated in later years. The USGS Crustal Strain project collected GPS data over southern California, from 1990 on, most notably making regular postseismic measurements around several large earthquakes. The US Navy Geothermal Program Office collected a large volume of data spanning an important part of the Eastern California Shear Zone [McClusky et al., 2001]. A very large volume of data was collected by various groups as part of the studies referenced in section 1 . There have also been many measurements made, both by academic groups and by local government agencies, that have not been formally described in the literature, but which were of sufficiently high quality (5 or more hours of occupation with dual-frequency receivers each time) to be of potential value, even if not collected explicitly to measure crustal motion; Parks and Dial [1997] is an example. At six sites $(6024,6050,6052,6056,6072$, and 6106) we utilized single-frequency data in finding coseismic offsets from the Landers earthquake.

[13] We started by assembling these GPS data, and archiving them with correct metadata, notably the receiver and antenna type, antenna height, and station identification. Given the very heterogeneous nature of the data collection, this was a substantial (if nominally straightforward) task. In practice the information needed was available only on logsheets filled out when the data were collected. We therefore developed software to catalog these logsheets, to match logsheets with particular data files, to efficiently enter the relevant data into the RINEX header, and to match RINEX files with monument locations (using point positioning), since the names given to the files were often not a useful guide. A by-product of this effort was an index to all monuments observed, with consistent (and unique) identifiers. Altogether this archiving effort involved some 24,000 files (and 16,000 logsheets, now stored at IGPP/Scripps) collected at more than 1800 monuments. The final RINEX files, and indices to the data, are available through the SCEC Data Center (http://pfostrain.ucsd.edu/scecgps/gps_page. html).

\subsection{Continuous GPS Data}

[14] The first continuously operating GPS receiver in California was operated as part of the National Geodetic Survey tracking network from 1986 through 1992. Additional stations were added at NASA sites in 1989; as new generations of receivers became available it became feasible to install more stations, specifically for monitoring crustal motion. The lead in this was taken by the Permanent GPS Geodetic Array (PGGA), which had installed nine more sites by the start of 1994 [Bock et al., 1997]. In response to the Northridge earthquake, additional funding became available: this went first to a denser array in the Los Angeles area, and eventually to the SCIGN (Southern California Integrated GPS Network) array; when this was completed in 2001 there were more than 250 continuous sites in southern California. We used data from all of these, along with data from neighboring arrays of continuous GPS sites: the BARD network in central and northern California; the PANGA network in northern California, Oregon, and Washington; and the BARGEN network in Nevada. Most importantly, we have used data from 21 continuous sites in the stable part of the North America plate; these define our realization of a reference frame fixed to the North America plate [Blewitt et al., 2005].

\section{Data Processing and Analysis}

\subsection{GPS Data Processing}

\subsubsection{Phase Processing and Combination}

[15] The first steps in our GPS processing used the GAMIT and GLOBK software packages (http://www-gpsg.mit. edu [Herring et al., 2010]). We first used the GPS phase observations to estimate daily station positions simultaneously with orbital and atmospheric parameters. We included all survey-mode data and up to a dozen continuous sites with broad regional spread and consistently available data. We processed the data in 24-hour spans, usually starting at zero hours UTC, though if the survey-mode data were in short spans across this boundary the start time would be moved to avoid splitting the data. An initial solution used moderate a priori constraints on orbital and station parameters to resolve integer phase ambiguities [Dong and Bock, 1989; Feigl et al., 1993]. We weighted GPS data proportionally to the square of the sine of the elevation angle and omitted data below $10^{\circ}$. The carrier beat phase is converted to double-differences between satellite and station pairs [Bock et al., 1986; Schaffrin and Bock, 1988] to estimate site positions, satellite orbits, Earth orientation parameters (EOP), and tropospheric delays. We obtained orbital positions of the satellite by numerically integrating the initial conditions using a force model which includes lunar and solar perturbations, GEM-T3 gravity model truncated to degree and order 8 [McCarthy, 1992], and a nine-parameter model for the direct effects of solar radiation [Springer et al., 1999]. In modeling the motion of the stations, we included solid-Earth tides according to the IERS standards [McCarthy, 1992], and ocean loading interpolated from a global $0.5 \times$ 0.5 degree grid provided by H.-G. Scherneck [http://froste. oso.chalmers.se/loading/ref], computed for the tides given in the CSR4 ocean-tide model. Our model of the delay in the GPS signal due to the neutral atmosphere began with the model of Saastamoinen [1972] assuming a surface pressure of $1013.25 \mathrm{hPa}$ ), a surface temperature of $20^{\circ} \mathrm{C}$, and a water vapor partial pressure of $8.32 \mathrm{hPa}$. This zenith delay was mapped to the elevation angle of the satellite using the expressions of Niell [1996]. We then estimated corrections to this model every two hours using the Niell mapping function for the water vapor component. We also estimated constant $\mathrm{E}-\mathrm{W}$ and $\mathrm{N}-\mathrm{S}$ gradients in atmospheric delay for each session [Chen and Herring, 1997].

[16] For 1986-1989, when no accurate a priori orbits were available, we started from the broadcast ephemeris and used only loose constraints. After 1989 we used initial orbits from the Scripps Orbit and Permanent Array Center (SOPAC) (http://sopac.ucsd.edu/processing/gamit [Nikolaidis, 2002]) whenever available. A final solution, with constraints relaxed and ambiguities resolved, provided daily estimates of station and orbital parameters free of reference-frame assumptions.

[17] The loosely constrained estimates of these parameters, with their covariances, become "quasi-observations" to be combined with similar estimates from other processing [Dong et al., 1998]. Prior to 1993, we included all of the 
Table 1. Earthquakes Modeled

\begin{tabular}{|c|c|c|c|c|c|}
\hline \multirow[b]{2}{*}{ Date } & \multirow[b]{2}{*}{ Magnitude } & \multirow[b]{2}{*}{ Name } & \multicolumn{2}{|c|}{ Number of Stations } & \multirow[b]{2}{*}{ Model } \\
\hline & & & Coseismic & Postseismic & \\
\hline $1992: 114$ & 6.1 & Joshua Tree & 28 & & Bennett et al. [1995] \\
\hline $1992: 180$ & 7.3 & Landers & 452 & 116 & Hudnut et al. [1994] \\
\hline $1994: 017$ & 6.7 & Northridge & 139 & 38 & Wald et al. [1996] \\
\hline 1994:029 & 5.5 & aftershock & 13 & & Donnellan and Webb [1998] \\
\hline $1999: 289$ & 7.1 & Hector Mine & 373 & 97 & Ji et al. [2002] \\
\hline 2003:052 & 5.3 & aftershock & 1 & & \\
\hline $2003: 356$ & 6.5 & San Simeon & 34 & & Ji et al. [2004] \\
\hline
\end{tabular}

available regional and global data in the same GAMIT analysis. For most surveys after 1993, we processed the survey-mode data separately, and then used the GLOBK software to combine them with quasi-observations produced from global and regional continuous data by SOPAC.

[18] Perhaps surprisingly, the very earliest data, in 1986, were not much more difficult to analyze than more recent data: in particular, cycle slips could be removed using automatic editing. The weaknesses of these early data are the sparse constellation of satellites and sparse network of global tracking stations used for orbits. For data collected in 1990 and 1991, processing became more challenging because of higher ionospheric activity; the limitations of codeless receivers used in both global tracking networks and in California surveys; and a difference of $0.08 \mathrm{~s}$ in the sampling times of different types of receivers [Feigl et al., 1991]. To address these last two problems, we processed separately the global and regional data from each group of receivers that shared a common time tag, and combined the solutions through orbit and Earth orientation parameters. The difficulties with data from the 1990-91 period are especially unfortunate given the relatively large volume of data collected then, as well as the importance of these data for getting station velocities before the 1992 Landers earthquake.

[19] A separate receiver timing issue was a time-tag offset of about 45 microseconds in the L1 and L2 phase data for the early Ashtech L-series receivers; Appendix A describes the effects of this, and how we corrected for it.

[20] To save subsequent computation time and to generate more meaningful long-term statistics, we aggregated these daily solutions into multiday combinations, where the time span implied by "multiday" varied from one day (immediately after large earthquakes) to forty days; Figure S2 of the auxiliary material shows the distribution of times. During aggregation we included a priori secular site velocities (found from previous solutions) to minimize biases from averaging over time. The final multiday combinations were again loosely constrained positions and EOP, with their covariances.

\subsubsection{Data Editing}

[21] We next generated time series of the daily and multiday GPS position estimates for editing. In both cases we defined a reference frame for the daily or aggregated solutions using a seven-parameter transformation: translation, rotation, and scale at each epoch to minimize the differences in position for six or more stations from a priori coordinates determined from a previous solution. This procedure was necessarily iterative since the number of stations with known coordinates and velocities for the early years was limited. We began by using North American stations from the International Terrestrial Reference Frame, epoch 2000 (ITRF2000) [Altamimi et al., 2002], but eventually added both continuous and survey-mode stations from our own solutions. As we added stations to the reference frame, the time series became increasingly stable. This approach has the advantage that a large number of stations are available at each epoch to estimate the translation, rotation, and scale parameters, allowing easy exclusion of outliers. We believe that this approach is quite robust and powerful compared to solutions relying on a few fiducial sites.

[22] Using the resulting time series, we edited the data, removing outliers and identifying steps due to changes in instrumentation (mostly antennas). The generation of the time series, including the choice of reference stations, and the subsequent editing, were performed independently at UCLA, using the QOCA software (http://gipsy.jpl.nasa.gov/ qoca [Dong et al., 1998]), and at MIT, using GLOBK. Although both analyses used a three-sigma criterion for removing outliers, the editing was not exactly the same because of choices made for reference stations and downweighting of noisy data. As described below, the final CMM result came only from the QOCA combination, the GLOBK combination being used as a check.

\subsubsection{Estimating Secular, Coseismic, and Postseismic Motions}

[23] After data editing, we combined all of the multiday quasi-observations into a single solution in which we modeled station position in each coordinate as a function of time by an initial position $x_{0}$ at time $t_{0}$, a velocity $v$, coseismic (and when needed instrumental) steps $a_{i}$, and postseismic displacements $D_{j}$ : with time-dependence

$$
\begin{array}{r}
x(t)=x_{0}+v\left(t-t_{0}\right)+\sum_{i} a_{i} H\left(t-t_{i}\right) \\
+\sum_{j} D_{j} \log _{10}\left(1+\left(t-t_{j}\right) / T_{j}\right)
\end{array}
$$

where the first sum includes earthquakes and other steps at times $t_{i}$, the second sum includes only some earthquakes, and $T_{j}$ is a time constant, assumed to be the same for all stations for each earthquake. This part of the analysis was performed independently at UCLA and MIT with different assumptions about the model. The UCLA analysis estimated coseismic offsets for stations for which the slip models given in Table 1 predicted displacements greater than $3 \mathrm{~mm}$. We used these predicted offsets as a priori constraints, with uncertainties given by $\left[\left(0.6 A_{i}\right)^{2}+\left(0.3 A_{j}\right)^{2}+\left(0.3 A_{k}\right)^{2}\right]^{0.5}$ for the $i$-th component, with $A_{i}, A_{j}$, and $A_{k}$ being the predicted offsets for any combination of the east, north, and up components. We found that these constraints are loose enough to have little 
A. Postseismic Data: Landers

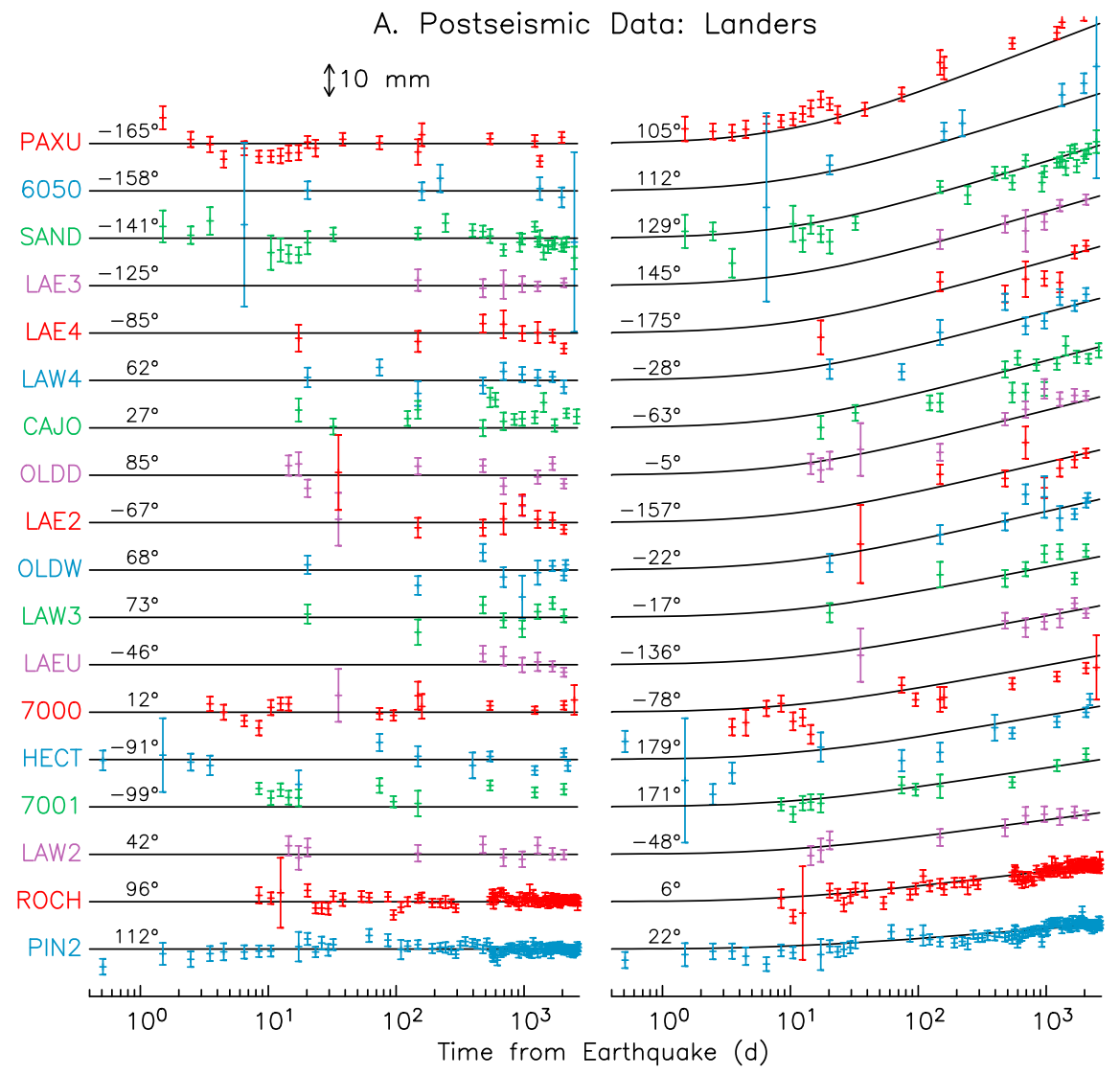

B. Postseismic Data: Hector Mine

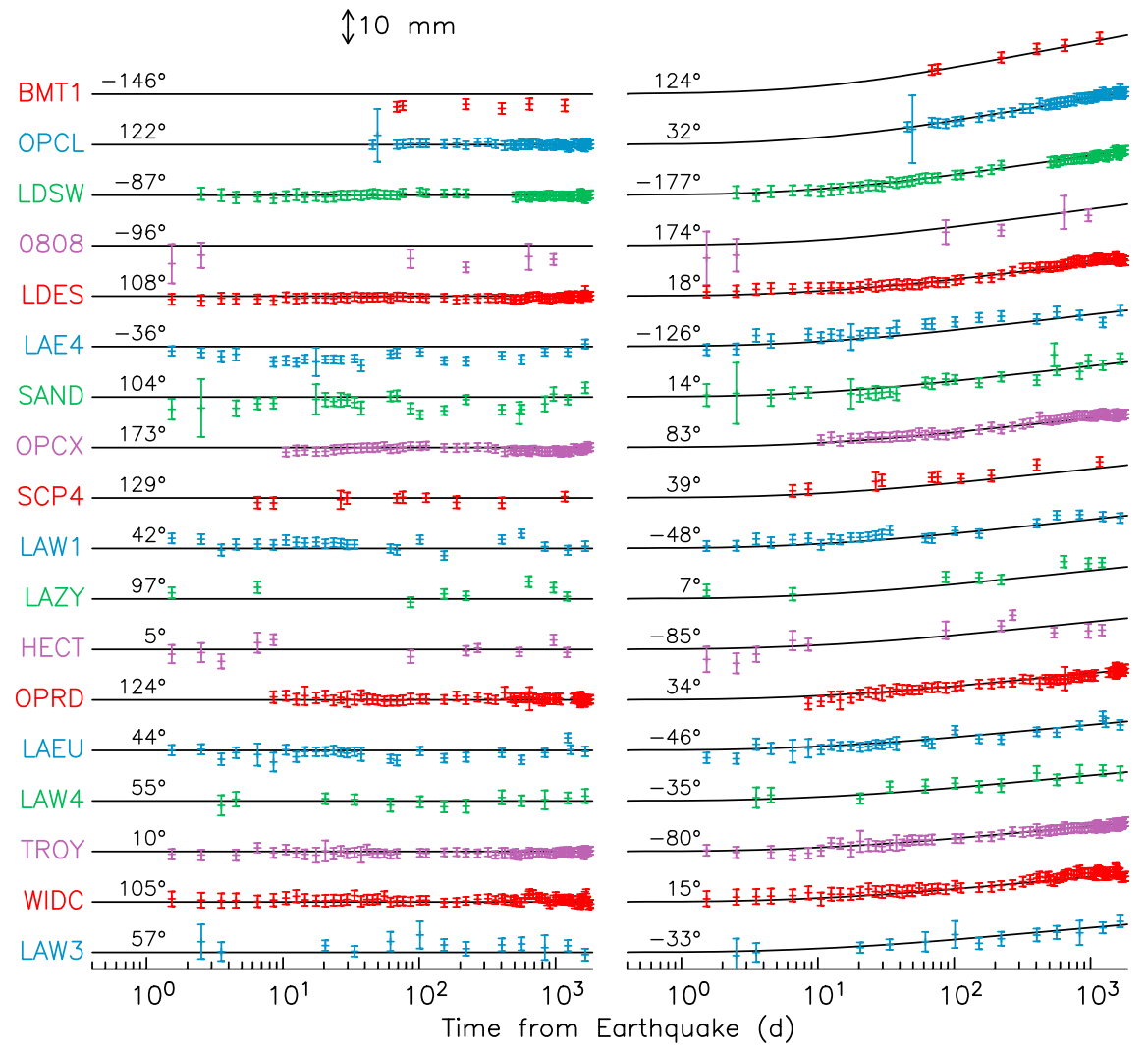

Figure 3 
effect if the data constrain the offset, but stabilize the solution if they do not. We included postseismic displacements only for sites whose predicted coseismic displacements exceeded $30 \mathrm{~mm}$ (for survey-mode sites) and $20 \mathrm{~mm}$ (for continuous sites). The amplitude $D$ was constrained a priori to be $10 \%$ of the predicted coseismic offset, with an uncertainty of $\left[\left(0.1 A_{i}\right)^{2}+\left(0.05 A_{j}\right)^{2}+\left(0.05 A_{k}\right)^{2}\right]^{0.5}$; again, this uncertainty stabilizes the solution without biasing it. The time constant $T$ was not estimated explicitly; trial and error showed that a value of 10 days fits most postseismic displacements adequately. Figure 3 shows the fit of the logarithmic function to several time series of station positions. The reference frame for the UCLA solution was realized by a seven-parameter transformation of the velocities of 20 continuous stations, to minimize the differences from the velocities given in the Stable North American Reference Frame (SNARF 1.0) [Blewitt et al., 2005], which gives positions and velocities of continuous GPS stations corrected for motion caused by glacial isostatic adjustment (GIA).

[24] The MIT analysis included no parameters for postseismic motion but omitted the observations for the period following each earthquake in which non-linear motion was apparent in the times series (2.5 years for Landers, 3.5 months for Northridge, and 2.2 years for Hector Mine). The reference frame was defined with only nine stations minimally affected by GIA. Figure S3a of the auxiliary material shows the differences in horizontal velocity between the UCLA and MIT solutions. There is a systematic difference of $-0.6 \mathrm{~mm} / \mathrm{yr}$ (UCLA-MIT) in east, and $0.6 \mathrm{~mm} / \mathrm{yr}$ in north, which likely results from a combination of different choices of reference stations, and differences in editing the data from the reference stations chosen. After removing this bias, most of the differences are less than $1 \mathrm{~mm} / \mathrm{yr}$; those greater than $2 \mathrm{~mm} / \mathrm{yr}$ are mostly stations for which the error of the difference is relatively large. (For example, about $70 \%$ of the differences that are less than $2 \mathrm{~mm} / \mathrm{yr}$ have errors less than $1.5 \mathrm{~mm} / \mathrm{yr} ; 70 \%$ of the differences that are more than $2 \mathrm{~mm} / \mathrm{yr}$ have errors that exceed this level). Figure S3b of the auxiliary material shows where stations with larger differences are located: these tend to be in regions around the three large earthquakes, for which the velocity difference may reflect the different approaches to handling post-seismic motion. Other sites with large differences probably reflect different choices in data editing.

[25] In our final estimate of velocities, we have made ties in velocity between stations within $1.5 \mathrm{~km}$, since we expect negligible tectonic deformation between them; in section 4 we discuss the inter-site motions for these pairs if no ties are made. We have excluded from our results any velocities with horizontal uncertainties greater than $3 \mathrm{~mm} / \mathrm{yr}$, coseismic steps with uncertainties greater than $0.1 \mathrm{~m}$, and postseismic displacements with uncertainties greater than $5 \mathrm{~mm}$. We also removed some velocity outliers that are clearly at odds with neighboring sites and are likely of non-tectonic origin (section 4.3). The final result has 1003 GPS site velocities in the area studied; since there are 73 GPS-GPS local ties the number of independent GPS velocities is 930 .

[26] As a final step in the GPS analysis, we regenerated the time series, this time using as reference stations for the seven-parameter transformation all of the stations in the solution for which the data have not been edited and the velocity uncertainty was less than $2.0 \mathrm{~mm} / \mathrm{yr}$. The a priori values of initial positions, velocities, and coseismic and postseismic motions for these stations were taken from the final GPS solution, and postfit residuals of the sevenparameter transformations are minimized in the least squares sense.

\subsection{Combining GPS, Trilateration, and VLBI Velocity Solutions}

[27] Our next step was to combine the GPS velocity estimates with the results from the other data types discussed in section 2. There have been many GPS measurements at trilateration stations or at locations nearby; these points (shown in Figure S4 of the auxiliary material) provide ties between the trilateration and GPS solutions. We combined the trilateration solution (section 2.1) with GPS-based velocities using 70 tie points, giving station velocities at 190 trilateration stations, again after removing outliers and sites with velocity uncertainties greater than $3 \mathrm{~mm} / \mathrm{yr}$. We did not find any detectable systematic differences between the GPS and trilateration velocity fields, though it is not clear if this is because the large number of ties forces the trilateration velocities to match the GPS velocity field, or because the secular velocity field has not changed.

[28] The VLBI data analysis (T. A. Herring, unpublished manuscript, 1995) estimated vector baselines between pairs of stations from the VLBI group delay; these were aggregated into a solution for station velocities with covariances (see Herring et al. [1990] and Ma and Kusznir [1994] for methods). We then combined the VLBI velocity solution with the GPS one by tying the horizontal velocities of six GPS-VLBI co-located stations in North America; this added 16 VLBI site velocities in southern California and helped strengthen the reference frame of some GPS sites which were surveyed during the early years only.

[29] The final CMM4 velocity field thus combined the loosely constrained GPS solution produced at UCLA with the trilateration and VLBI solutions. The velocities were referenced to SNARF 1.0 through a seven-parameter transformation that minimizes the residual velocities for the 20 sites indicated in the table of site velocities, in the auxiliary material. The auxiliary material also contains tables giving the site locations, coseismic and postseismic displacements, and the times and amounts of estimated

Figure 3. (a) The modeled and observed postseismic motions following the Landers earthquake. For each location, the left panel shows displacements perpendicular to the modeled postseismic motion, and the right panel displacements in the direction of this motion. For each station and component the line shows the predicted displacement, which in the left plot is zero by definition; on the right, because of the logarithmic timescale, the prediction starts out flat but at long times becomes an apparently linear trend. The numbers above each line give the component azimuths. The points with error bars are the observations, with secular motions removed; these are color-coded to make them easy to separate visually. The stations are ordered by size of the postseismic signal. (b) The same information for the 1999 Hector Mine earthquake. 
instrumental offsets at GPS sites; the auxiliary material also contains the time series of GPS station positions, expressed as residuals from the model.

\section{Error Analysis}

[30] One of the most challenging aspects of this analysis has been to produce realistic errors for the parameters estimated. It is very important for the errors to be correct, since we can decide that significant motion takes place between two points only on the basis of both the velocities and their errors. Nominal errors can be found by starting with the residual RMS of the fit to the original GPS doubledifferenced carrier-beat-phase, and propagating these errors forward into the final parameter fits. But since this formal procedure neglects other sources of variability, it invariably underestimates the true uncertainty, and also usually assumes the errors to be uncorrelated over time.

[31] We assess errors in the following ways: first, we examine possible systematic errors; next, we discuss the error models that have been applied to propagate different sources of noise into the final parameter estimates. We then examine the solution to evaluate the errors, both by comparing nearby stations and by examining the residuals from a tectonic model. We also describe how we edited data and eliminated outliers by evaluating the spatial coherency of the deformation fields and the displacement time series.

\subsection{Systematic Errors}

[32] We define systematic errors as biases in position or velocity estimates that are common to one of the measurement techniques or, for a given technique, common to a particular region or period of time. Scale bias between trilateration and GPS, mentioned earlier, is a clear example, but one that can be accounted for by estimating a scale parameter in the combination. A more difficult scale problem arises in GPS because of the evolution of the satellite constellation. Between 1986 and 1989, the constellation was dominated by Block I satellites, which were gradually replaced by Block II and IIA (1989-1997) and then Block IIR. These four satellite designs each had a different antenna, and the pre-launch specifications do not adequately model the phase pattern of any of them. Changes in the constellation thus caused changes in apparent distance to the satellites (and hence scale) over the span of our measurements [Zhu et al., 2003; Ge et al., 2005]. While some of this mismodeling may be corrected by future reprocessing of the global and southern California data sets, the necessary corrections are unlikely to be available for the Block I satellites; our results thus may have time-dependent scale errors that could bias vertical rates by $1-2 \mathrm{~mm} / \mathrm{yr}$. There may also be centimeter-level errors in modeling of the phase centers of many antennas used for survey-mode measurements, and unidentified discontinuities in the continuous time series due to changes in instrumentation. Finally, the reference frame (SNARF) is itself uncertain, especially in the vertical, because of incomplete modeling of vertical and horizontal motions caused by GIA in North America.

[33] For horizontal velocities, the most important systematic error is a bias or distortion of a network of sites used for a single survey, leading to spatially coherent changes in velocities that can mimic crustal deformation. These errors can arise from errors in orbital modeling or unmodeled satellite signal propagation delays that affect fiducial stations used to define the reference frame for a survey; they are far more likely to have occurred for the earliest measurements when the satellite constellation and the fiducial network were much more sparse. The most reliable way to avoid these errors is to have long and well-populated time series and to look for inconsistencies between velocities of nearby sites estimated from data from different time periods. In our current analysis, we have included stations measured as few as three times over at least two years, but rely on stations with many more measurements to check these poorly observed stations.

\subsection{Error Models}

[34] Studies of continuous GPS observations have shown that the error spectrum for most stations can be reasonably represented by a combination of white noise and flicker noise, that is, a noise component that is constant at all averaging times and one that increases as the inverse of the sampling frequency [see Williams et al., 2004, and references therein]. Although the flicker noise component can be estimated from time series, it cannot easily be implemented in a simultaneous estimation of parameters from all of the data. However, a random walk process (noise increasing as the inverse square of the frequency) can be implemented in both QOCA and GLOBK and provides a useful surrogate for processes with lower spectral index, particularly since the relevant errors for secular motion are the ones that dominate at the longest time spans.

[35] For 286 of the 359 continuous stations in our solution (most with spans greater than 4 years), we determine the random walk to be applied using the "realistic sigma" algorithm of Herring [2003] and described by Reilinger et al. [2006]. In essence, this algorithm evaluates the decrease in scatter as a function of averaging time and compares this with the decrease to be expected for white noise. From these values, we then estimate parameters of a first-order Gauss-Markov process that can be used to obtain the random-walk value that best predicts the velocity uncertainty for the span. Ninety percent of the random-walk values for the horizontal component at these 286 continuous stations range from 0.25 to $0.65 \mathrm{~mm} / \sqrt{a}$, with a median of $0.35 \mathrm{~mm} / \sqrt{a}$. For stations observed either episodically, or continuously for short time spans, we use a set of constant values of $1.0,1.0$, and $2.0 \mathrm{~mm} / \sqrt{a}$ for the east, north and up components, determined by evaluation of the velocity residuals, as described in section 4.4. In a few cases we assigned lower or higher values to survey-mode sites, either because they had especially dense time series or because the time series revealed excessive variability.

[36] The uncertainties in the initial trilateration data (line lengths) were taken to be the errors assigned by Savage and Prescott [1973] to the individual data values. As described by Dong [1993], an analysis of the scatter of the data around a linear trend, conducted for different subnetworks of the trilateration stations, showed a slightly higher distanceindependent error [see also Johnson et al., 1994], but this difference was small enough that the Savage and Prescott values were deemed acceptable. 

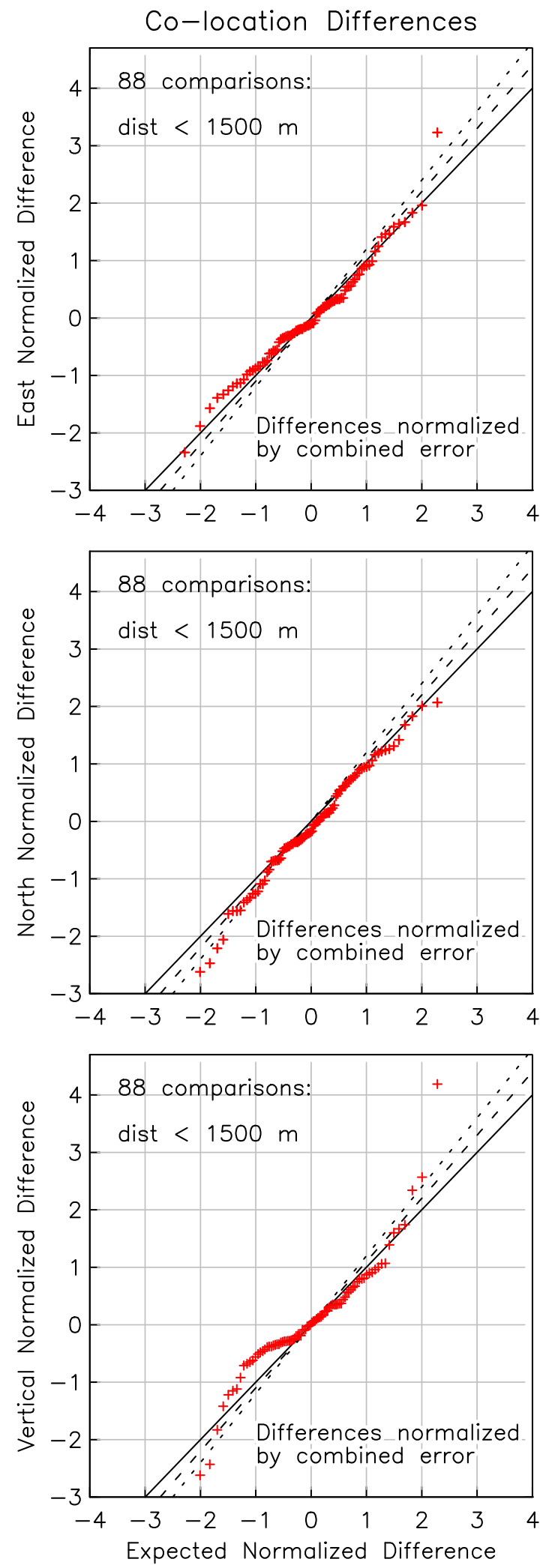

Figure 4. Q-Q plots of the standardized velocity differences, for each component, between closely spaced GPS points, in a solution in which such points were not tied. The red crosses are the differences; the solid line is the expected distribution if the errors are correct, while the dashed lines correspond to increasing the errors by $10 \%$ and $20 \%$.

\subsection{Data Editing and Removal of Outliers}

[37] As mentioned earlier, bad position estimates were detected during the analysis steps, and were screened, edited, and/or removed in an objective way. We began by examining the station time series after fitting the model (1) and removing, as outliers, values that deviated more than three standard deviations from their model predicted values. These outliers were usually caused by blunders in antenna setups, incorrect ambiguity resolution, large satellite orbital errors, or large errors in modeling of troposphere time delay. For continuous sites we also estimated offsets at times recorded in the processing logs maintained by SOPAC. Some time series, mostly from sites in geothermal areas, showed transient displacements; we enlarged the uncertainties of the corresponding components by a factor of 10 to 100 , depending on the scale and frequency of the transient signals.

[38] Finally, we inspected the spatial consistency of the horizontal velocity, coseismic, and postseismic deformation fields, and removed site velocities which were clearly incompatible with their neighbors, except in regions spanning significantly creeping faults such as the San Andreas fault in central California and the Imperial fault. In general these discrepant results were not obvious in the time series because of too few station occupations; they may indicate local instability or a single poor observation. We have included these velocities in a separate table in the auxiliary material.

\subsection{Evaluating the Uncertainties in the Velocity Estimates}

[39] If our error model and data weighting are correct, we expect that, if there is no deformation, the standardized velocity residuals (velocity estimates with the true value subtracted, and the residual scaled by the standard error) will be distributed with zero mean and unit variance, and that this distribution will be approximately Gaussian. Of course, a direct test of this is not possible because all our stations are in a deforming area and the "true values" there are not known. One test is to compare our velocities with those computed by other methods for the same stations. Two other tests compare velocities in situations in which we believe there should be little deformation: one case is closely spaced stations, and the other is regions for which the deformation can be modeled with many fewer free parameters than the number of stations. This last method, used by McClusky et al. [2000], Davis et al. [2003], and McCaffrey et al. [2007] is the most complete, but also the most dependent on assumptions, since an inadequate model may produce a larger scatter in the residuals than is correct, while if the model absorbs measurement errors the residuals from it will have an unrealistically small scatter, causing the errors to appear too large. Using regions with large crustal blocks, simple geometries, and slow-moving faults gives the most confidence that the residuals from a model accurately represent errors in the measurements.

[40] In part because we included data from many sources, we have a relatively large number of velocities at stations spaced closely enough that we expect no significant tectonic motion between them: in many cases such pairs include one survey-mode and one continuous site. For a separation distance of $1500 \mathrm{~m}$ or less, we had 88 such pairs, for which 
A. Model Comparison Areas

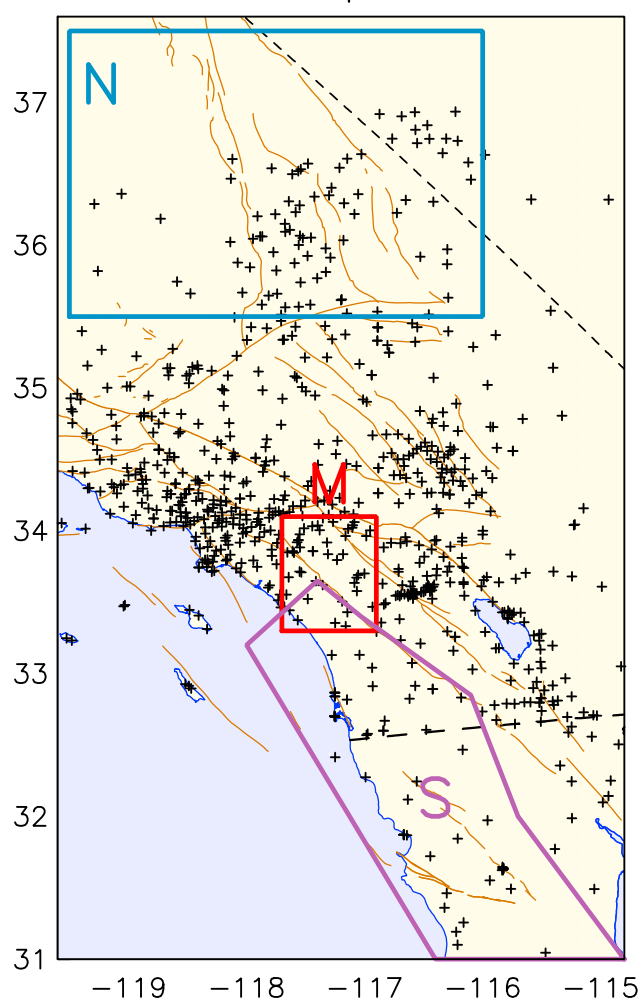

B. Model Comparison
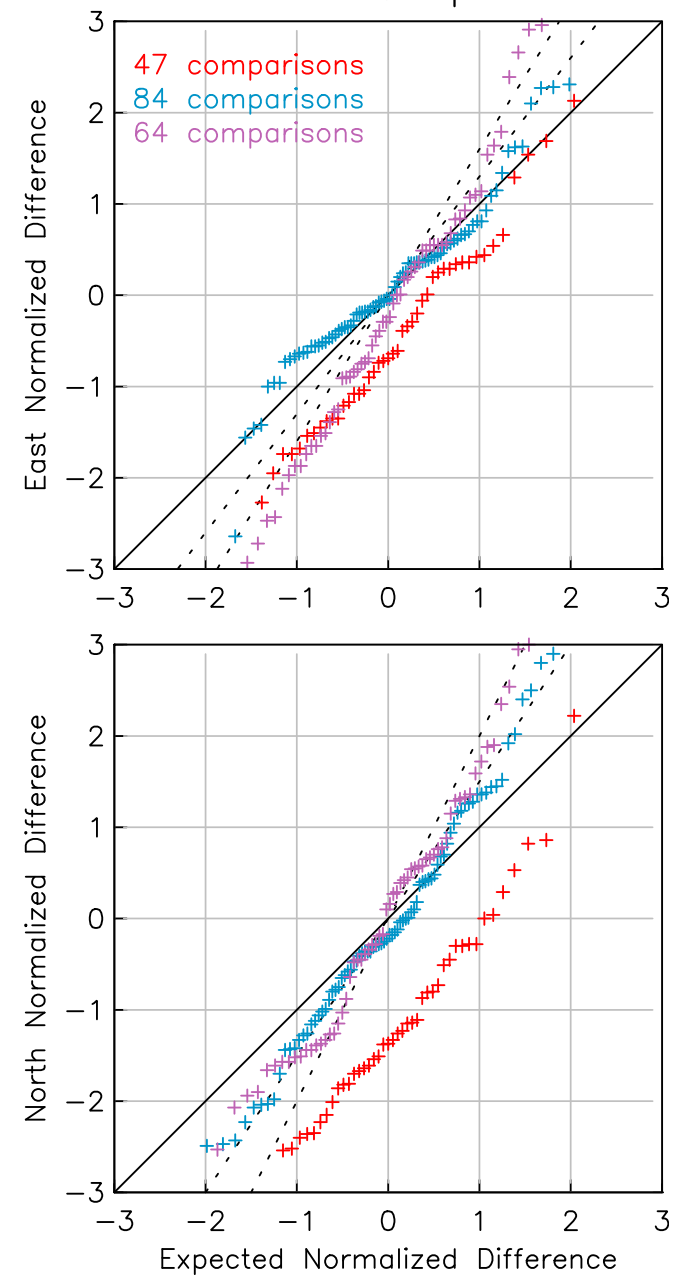

Figure 5. Figure 5b shows Q-Q plots of the residuals, for the two horizontal components, between the CMM velocities and a block-model prediction of them, scaled by their errors, and shown for stations in the three regions shown on the map (Figure 5a). The solid line is the expected distribution if the errors are correct, while the dashed lines correspond to increasing the errors by $30 \%$ and $60 \%$. See text for discussion.

we calculated the velocity differences, normalized by the combined standard errors from each site. As noted above, if the errors assigned are correct, the results should appear to be Gaussian random variables with zero mean and unit variance. Figure 4 shows the actual distribution of the differences for the three components of velocity, plotting the empirical cumulative distribution function (cdf) against that for a standardized Gaussian. The cdf lies close to the 45degree line in each case, showing that the differences have the appropriate distribution; applying a Kolmogorov-Smirnov (K-S) test to the empirical cdf confirms that there is no significant departure. While the plot suggests that the distribution for the differences in the vertical has a smaller variance (by $30 \%$ ) than would be expected, the K-S test also shows that the observed distribution in that case is still acceptably close to a unit-variance Gaussian.

[41] To assess the uncertainties more broadly, we used velocities for a block model that used the methods of McCaffrey [2005], but that was fit to the CMM data (R. McCaffrey, personal communication, 2007) to remove block rotations and elastic strain from the CMM, and examined three areas where the resulting velocity residuals appeared to be nearly random. These areas are shown in Figure 5: they include eastern California and Nevada (N), the region of the central San Jacinto and Elsinore faults (M), and the onshore region south and west of the Elsinore fault, including northern Baja California (S). In all the three regions, we examined the number of residuals that fell outside the $70 \%$ error ellipse for velocity estimates found during test runs with different default values for the random-walk parameter applied to the survey-mode and short-span continuous stations. The normalized residuals for a value of random-walk noise of $0.5 \mathrm{~mm} / \sqrt{a}$ produced error ellipses that were too small; in region $\mathrm{N}$ the normalized residuals for survey-mode stations in California were more consistent with a random-walk value of $1.0 \mathrm{~mm} / \sqrt{a}$ (our final choice) than with one of $0.75 \mathrm{~mm} / \sqrt{a}$. We note that the 14 Nevada stations in region $\mathrm{N}$ are part of the western Basin and Range network [Wernicke et al., 2000; Davis et al., 2003], which have operated under nearly ideal conditions for GPS 
CMM (GVE21) vs PBO (20080930124552)

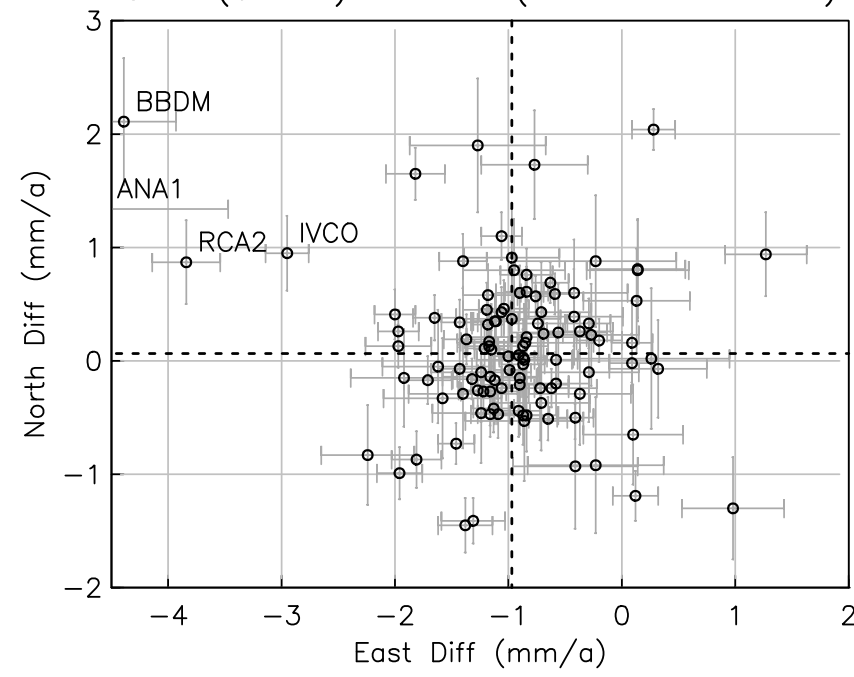

Figure 6. Scatterplot of horizontal velocity difference for stations in the CMM solution that have also been processed as part of the Plate Boundary Observatory, excluding stations in the Parkfield area (and AVRY, which is known to have been unstable). Note that there is little temporal overlap in these solutions. Stations with the largest discrepancies are labeled. The dashed lines show the weighted mean of the differences, excluding the labeled stations. Figure S6 of the auxiliary material shows these differences (including stations not shown here) in map form.

measurements: a long span of observations (5.5 years for our analysis) on deep-drilled braced monuments in a very arid region. The random walk values we estimated for these stations are all roughly $0.4 \mathrm{~mm} / \sqrt{a}$; but even these appear to be too large to represent the true uncertainties, since $85 \%$ of the velocity residuals fall within the $70 \%$ error ellipses. Figure 5 shows Q-Q plots of the normalized velocities within each region; these indicate that for regions $\mathrm{N}$ and $\mathrm{M}$ the scatter is consistent with the errors given (in region $\mathrm{M}$ there is a nonzero mean, but this does not affect the analysis of errors); in region $\mathrm{S}$ the normalized velocity residuals suggest that the errors may be underestimated by about $30 \%$.

[42] We conclude that the errors given for horizontal velocities in the CMM are appropriately scaled. Since there is some evidence that they may be underestimated in some regions, users of the results may wish to scale the errors up by a factor of 1.1 to 1.3 if they wish to be conservative in their conclusions.

[43] We have compared our horizontal velocities with the velocities estimated by the Plate Boundary Observatory, for those stations (largely the SCIGN continuous sites) that have been used in both solutions. For the PBO analysis we used (release date 09/30/2008) the PBO data extend from 2004.0 through 2008.6, and are thus largely independent of the CMM data, which end at 2004.73; the analyses of the data are completely independent. Figure 6 shows the scatterplot of differences in horizontal velocity. There is a systematic difference of $-0.97 \mathrm{~mm} / \mathrm{yr}$ in the east, and $0.06 \mathrm{~mm} /$ $\mathrm{yr}$ in the north. After allowing for this most of the differences are less than $1 \mathrm{~mm} / \mathrm{yr}$, though there are a few stations with larger discrepancies. Figure S5 of the auxiliary material shows the locations of these sites; those with large differences do not appear to have any systematic distribution, aside from a concentration around the location of the Parkfield earthquake (2004.74).

\section{Vertical Motions}

[44] As described in section 4.1, there are several additional sources of error in vertical rates measured with GPS; for survey-mode stations yet another is that observers are more likely to err in measuring antenna height than in centering the antenna over the mark. We are thus less certain of the true uncertainties in vertical velocities. Nevertheless, we have included these estimates in the CMM. Figure 7 shows the vertical velocities for 464 GPS stations with consistent time series and uncertainties less than $1.95 \mathrm{~mm} /$ yr. Because of the possibility of reference frame bias, we have removed a mean value of $-1.1 \mathrm{~mm} / \mathrm{yr}$ from the tabulated rates before plotting, to show relative rates more clearly. We also believe that actual ground motion should be inferred from these estimates only if the velocities are spatially coherent across a broad area. We see downward motion in the Salton Trough, which is what would be expected for an area of rifting; and also in parts of the Los Angeles region in which groundwater withdrawal is known to be causing subsidence [King et al., 2007]. There appears to be a region of uplift running north-south across the eastern end of the Transverse Ranges and into the area of the Landers earthquake, and, less definitely, along the Ranges as a whole.

[45] As with the horizontal velocities, we have compared our vertical velocity estimates with those available from the PBO analysis for stations that both solutions have in common. Figure S6 of the auxiliary material shows the result in map form. The weighted mean of the difference, excluding the stations in the Parkfield region, is $-2.8 \mathrm{~mm} /$ yr; after removing this, two-thirds of the vertical velocities (72 stations out of 112) differ by $1 \mathrm{~mm} / \mathrm{yr}$ or less, and $90 \%$ by $2 \mathrm{~mm} / \mathrm{yr}$ or less.

\section{Discussion}

[46] The main purpose of the paper is to present the results of CMM4, not to offer models or interpretations. However, we can report several new results; we also summarize the general features of the velocity field.

[47] Our first result is that it is possible to get very good estimates of horizontal, and even of vertical, motion using only occasional ("campaign" or "survey-mode") GPS measurements. GPS data recorded continuously at permanent sites is a vital tool for examining seismic or aseismic transients. But if the only expected result from measurements is the long-term velocity, it may be desirable to trade the cost of running a permanent network for the lower cost (but longer time needed) of survey-mode data, especially because correlated noise means that the number of measurements is much less important than the length of time they span [Johnson and Agnew, 1995]. Figure 8 shows what is possible in estimating vertical velocities. The left panel shows that the distribution of vertical velocities from the survey-mode sites with the lowest errors is very close to the 


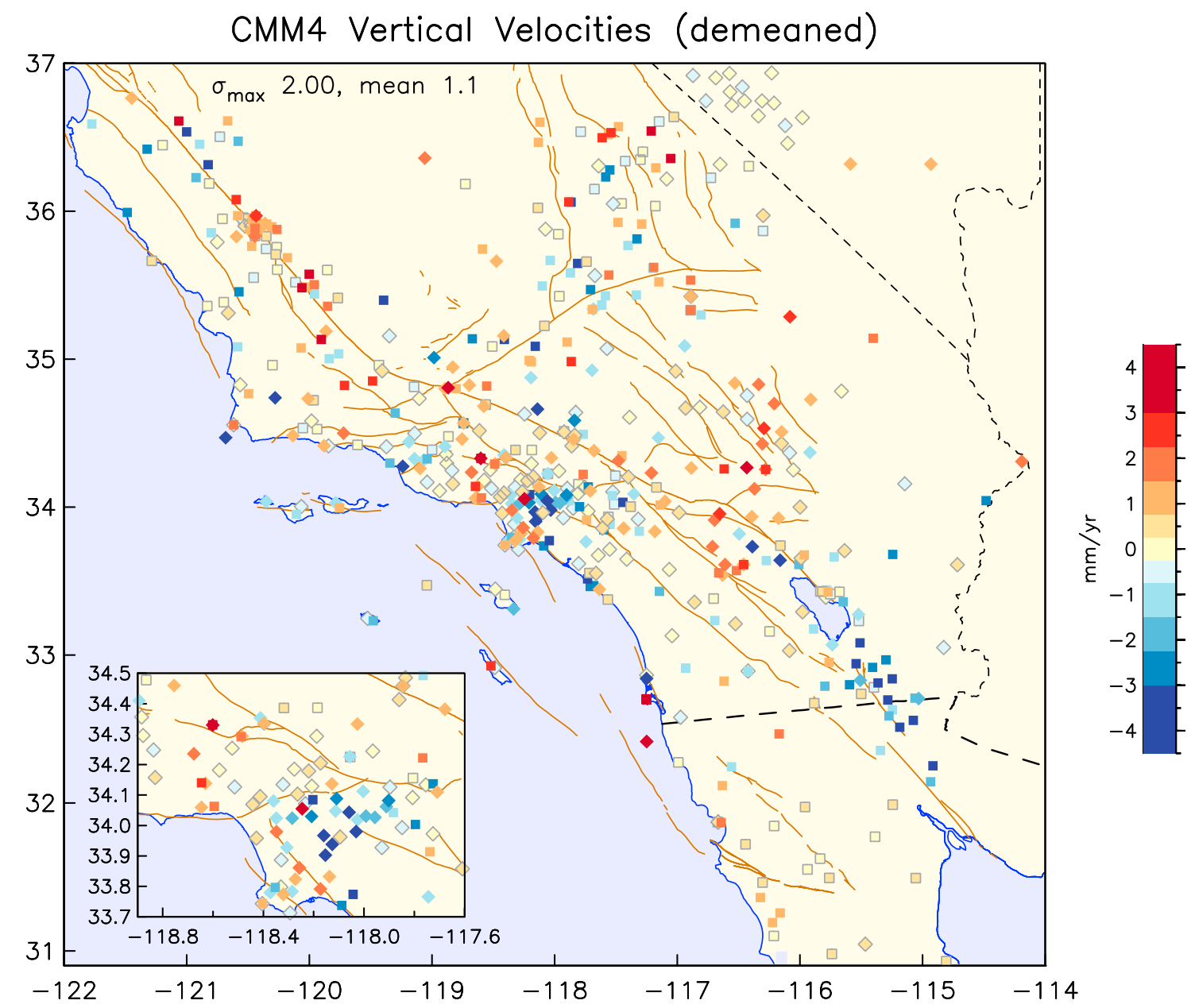

Figure 7. The vertical velocities of CMM stations with errors of less than $1.95 \mathrm{~mm} / \mathrm{yr}$; the mean value of $1.1 \mathrm{~mm} / \mathrm{yr}$ has been removed. Continuous GPS stations are indicated by diamonds and survey-mode ones by squares: the symbol is colored according to the velocity, as shown in the scale on the right. Though there is considerable scatter, areas of subsidence are clearly visible in the Salton Trough and the Los Angeles basin (inset); a less well-defined area of uplift occurs along the Transverse Ranges.

distribution of velocities from permanent sites. The right panel displays the survey-mode sites in terms of the total time span of data and the number of epochs, and shows that low enough errors can be obtained with several measurements spanning a decade.

[48] Figure 9 summarizes the CMM results for coseismic and postseismic motions for the two largest earthquakes (Landers and Hector Mine); Figure S7 of the auxiliary material does the same for the two other earthquakes for which we estimated postseismic motions. These plots show that for all four large earthquakes, the postseismic motions are mostly in the same direction as the coseismic ones, with the amplitude ratio of coseismic to postseismic clustering around a value of $10-20$. It is notable that this behavior is common to all the events analyzed, even though two of them are strike-slip and two others are thrusts; this result suggests that the early postseismic motions modeled by equation (1) may be primarily caused by slip similar to the coseismic rupture.

[49] Finally, Figure 10 shows the horizontal velocity field, which on this broad scale is best displayed in coordinates parallel and perpendicular to the local direction of plate motion. Plotting velocity vectors gives an uninterpretable jumble; we instead display the velocities in a series of profiles perpendicular to the direction of plate motion, showing plate-parallel and plate-normal profiles separately. Moving from northwest to southeast along the boundary:

[50] 1. Profile A shows the abrupt step in velocity across the creeping section of the San Andreas fault, with little deformation east of it and a small amount to the west [Rolandone et al., 2008], while profile B shows the broadening of the zone of deformation associated with the transition to a locked fault at Parkfield [Segall and Harris, 1987; Murray and Langbein, 2006].

[51] 2. The western end of profile $\mathrm{C}$ shows the fully developed zone of strain accumulation around the Carrizo segment of the San Andreas fault, including the puzzling asymmetry of the velocity profile [Schmalzle et al., 2006]. To the east, this profile, though sparse, clearly indicates the stable region of the Sierra Nevada microplate, terminated on the east by the Eastern California Shear Zone (ECSZ) in the Owens Valley. 

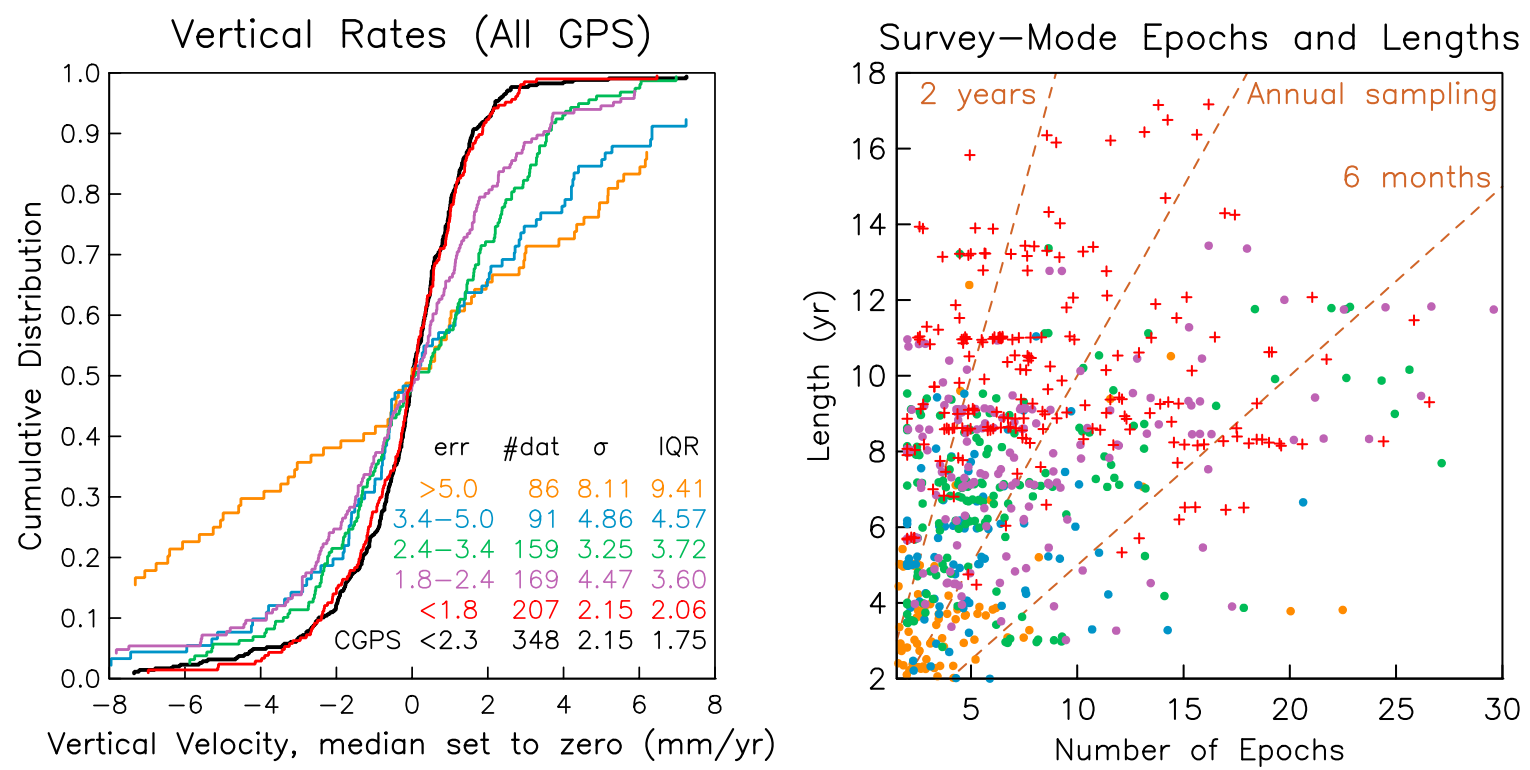

Figure 8. (left) The actual distributions of the vertical velocities for different sets of survey-mode GPS points, grouped by model error (colored) and for continuous GPS points with low errors (black). The actual statistics indicate that the vertical errors on the survey-mode points may be slightly underestimated, but also that the survey-mode points with low errors have a very similar distribution to the continuousGPS points. (right) How the vertical error depends on the number and timespan of observations, with colors matched to the left (the lowest-error points are shown as plus signs). The dashed lines show where stations observed biannually, annually, and semiannually would fall.

[52] 3. Profiles $\mathrm{D}$ and $\mathrm{E}$, which include the Transverse Ranges and the Mojave ("Big Bend") portion of the San Andreas, have the broadest region of deformation. Comparing $\mathrm{D}$ and $\mathrm{E}$ shows the merger of the ECSZ into the overall plate boundary (see Spinler et al. [2010] for a more detailed view). These two profiles also show the largest amount of motion perpendicular to the direction of plate motion, associated with compression along the Transverse Ranges and motion parallel to the San Andreas along the Big Bend.

[53] 4. The motion in Profile $\mathrm{F}$ is almost purely plateparallel, though the zone of deformation is over $200 \mathrm{~km}$ wide because it includes not just the San Andreas but also the San Jacinto and Elsinore faults. In addition, though not shown here, as much as $10 \mathrm{~mm} / \mathrm{yr}$ of motion remains to be taken up offshore in the California Borderlands.

[54] 5. Most of the deformation in profile $\mathrm{G}$ occurs over a much narrower zone associated with the Imperial fault and the Salton Trough, though again there is significant deformation well to the west, and in this profile the North American plate extends almost to the Imperial Fault. Further south, in profile $\mathrm{H}$, the zone of deformation associated with the main plate boundary (the Cerro Prieto fault) appears to be even narrower, though this may be an artifact of the very sparse sampling in this region.

\section{Conclusions}

[55] Through a unified analysis of various types of geodetic data collected in southern California for the period 1970-2004, we have created a spatially dense field of interseismic velocities for this area and time period, along with reliable estimates of the associated errors. We have also estimated coseismic displacements and postseismic motions from the four large earthquakes that occurred during this time period; these suggest that the pattern of immediate postseismic motion tends to resemble that of the coseismic displacements. Aside from these earthquake-related motions we do not see any indication of time variations. The interseismic velocities outline the concentration of strain around the San Andreas and associated faults, and also show the extension of deformation to the Eastern California Shear Zone north of the Transverse Ranges, and west to the California Borderlands south of the ranges. Vertical velocities, many obtained from survey-mode GPS data, show that over most of this region there is little vertical motion, with the main exception being in the Salton Trough, and (for probably non-tectonic reasons) in parts of the Los Angeles basin.

\section{Appendix A: Time-Tag Errors in Ashtech Codeless Receivers}

[56] While analyzing survey-mode data collected between 1991 and 1996 by several groups in southern California, MIT analysts noted an apparent bias in the east component of position when using data from Ashtech receivers that did not acquire the P2 code. The IGS code for these is ASHTECH L-XII; we term these "L2-codeless" receivers. To test for a timing error in these instruments, we used doubledifferenced phase data to estimate clock offsets between an Ashtech Z-12 and six codeless receivers within $50 \mathrm{~km}$ of it during two days in 1994. The estimates ranged from 22 to 64 microseconds, with uncertainties of 5 to 10 microseconds, with the best results (from two nearly co-located receivers) being $45 \pm 5$ microseconds. A large batch of southern California data acquired between mid-1992 and 
Hector Mine: Coseismic and Postseismic Horizontal Motion

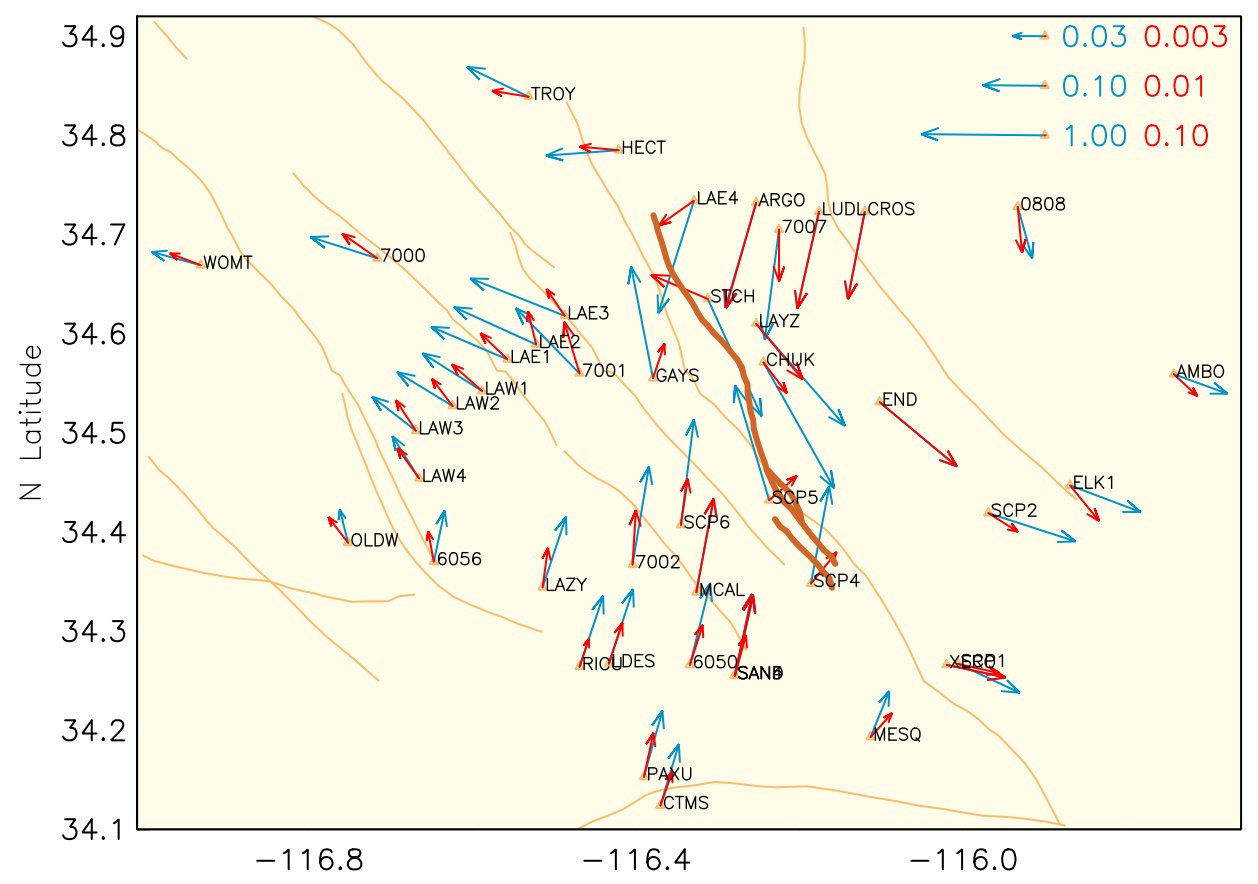

Landers: Coseismic and Postseismic Horizontal Motion

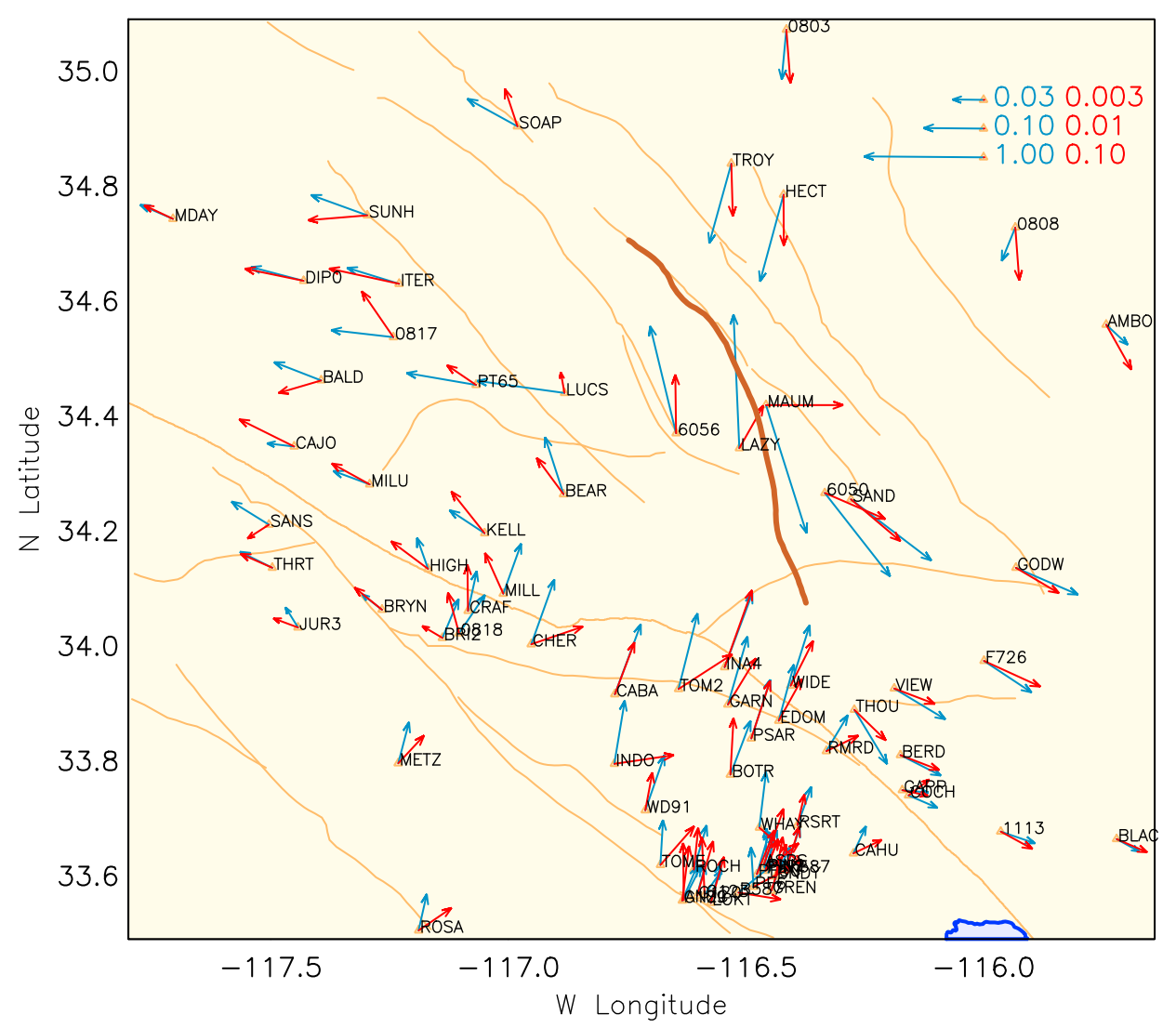

Figure 9. The coseismic (blue) and postseismic (red) horizontal motions for the Landers and Hector Mine earthquakes, for those locations at which both were estimated (in a few cases the arrows overlap). The scaling of the arrows is nonlinear; specifically, the arrow length on the map is given by $L=b$ arcsinh $(D / c)$, where $D$ is the coseismic displacement or the size of the logarithmic function describing the postseismic motion (see section 3.3). For both earthquakes, $c$ is $20 \mathrm{~mm}$ for the coseismic and $2 \mathrm{~mm}$ for the postseismic; for the Landers earthquake $b$ is $5 \mathrm{~km}$ and for the Hector Mine earthquake it is $3 \mathrm{~km}$. 


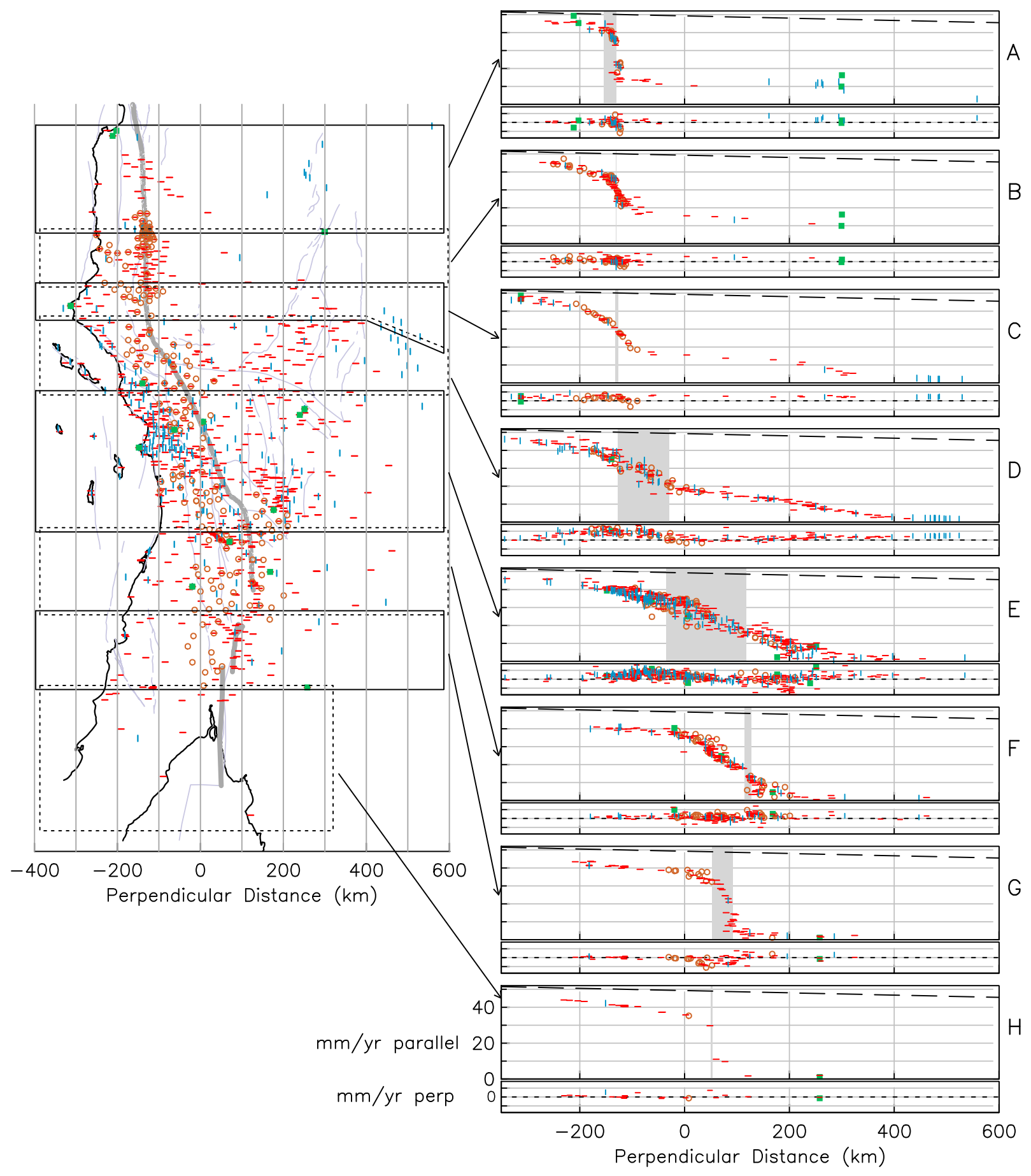

Figure 10. Locations and velocities of CMM points in a coordinate system centered on the Pacific/ North-America pole of rotation given by Argus et al. [2010]. On the left, the stations are plotted in an oblique Mercator projection [McKenzie and Parker, 1967] so that the $y$-axis is the local direction of plate motion; the zero of the $x$-axis is $7390 \mathrm{~km}$ from the pole of rotation, and active faults are in purple. In both plots survey-mode GPS stations are red horizontal lines, continuous GPS stations are blue vertical lines, trilateration points are brown circles, and VLBI sites are green squares. The boxes on the right, which correspond to regions outlined on the left, show velocities parallel (large box) and perpendicular (small box) to the direction of plate motion; the dashed line in each plate-parallel box is the amount of plate motion as a function of $x$. The velocity scales are the same for all boxes. The gray line on the map to the left is the main plate boundary: from NW to SE, the San Andreas fault, Imperial fault, Cerro Prieto fault, and its extension into the Gulf of California. The gray region in each box on the right shows the range of $x$ values covered by this boundary, from very small in the region around Parkfield (box B) to very large in the Big Bend area (boxes D and E). 
1995 were then reprocessed assuming no offset (case A), an estimated offset (case B), and a fixed offset of 45 microseconds (case $\mathrm{C}$ ). The baseline components for cases $\mathrm{B}$ and $\mathrm{C}$ generally agreed to within $1 \mathrm{~mm}$, compared with 20 $30 \mathrm{~mm}$ offsets, mostly in the east component, for case A.

[57] Because of changes in the Ashtech firmware to deal with Y2K problems, it was not possible to verify the offset using zero-baseline tests. Ashtech engineers (J. Ladd and R. Lorenz, personal communication, 2000) believe that a timing error would mostly likely come from a combination of hardware and software delays, and would be constant within 20-50 ns.

[58] This timing error means that Ashtech data must be examined to determine whether or not they came from codeless receivers. In principle, this can be done by looking for an absence of P1 and P2 data and for half-cycle slips in the phase. However, some RINEX translators allow P1 and P2 to be inserted into the header even if these observables are not present, or allow $\mathrm{P} 1$ and $\mathrm{P} 2$ observations to be omitted from the file if they are not requested in the translation. Codeless receivers can almost always be identified by the RINEX header containing a receiver code of LM-XII, L-XII, LM-XII, L-XII3, or LM-XII3, or firmware codes $6 \mathrm{~A}$ or $7 \mathrm{~A}$. The difficulty is to distinguish the L2-codeless systems from the "P-12" code-tracking receivers, which used P2 and do not have a time-tag error; these have IGS codes ASHTECH LM-XII3 and ASHTECH P-XII3. Such "P-12" receivers usually have firmware versions $6 \mathrm{C}, 6 \mathrm{G}$, or $6 \mathrm{M}$ and channel version P6, but RINEX files from them sometimes have the same firmware and receiver designations as the L2 codeless systems. For the CMM we could often use serial numbers to correct errors in these designations, reliably identifying codeless receivers.

[59] Acknowledgments. This project depended first and foremost on many efforts to collect trilateration data, survey-mode GPS data, and continuous GPS data. Trilateration data collection was begun by Jim Savage and Will Prescott; we thank them, and Mike Lisowski, for making the data available and resolving many issues. For the majority of our sites, the data came from survey-mode GPS measurements; we thank all those who organized such efforts, the very many observers who collected the data (often under trying conditions) and the landowners who provided access. For making such data available we especially thank Gerald Bawden (UC Davis), Tim Dixon (JPL/University of Miami), Don D'Onofrio (Caltrans), Andrea Donnellan (JPL), Javier Gonzalez-Garcia (CICESE), Brad Hager (MIT), Ken Hudnut (USGS), Dave Jackson (UCLA), Louise Kellog (UC Davis), Greg Lyzenga (Harvey Mudd), Meghan Miller (Central Washington University), Frank Monastero and Steve Bjornstad (US Navy Geothermal Program Office), William Prescott (USGS), Robert Reilinger (MIT), Jay Satalich (Caltrans), Karen Wendt (USGS), and the late Bill Young (Riverside County Flood Control). Michael Cline and Mercedes Kim (UCLA) collected a considerable volume of data with SCEC funding. We thank David Potter, Steve Salyards, and Li-Yu Sung (UCLA) for the initial data assembly. At UCSD, Hadley Johnson and Greg Anderson developed and implemented the software and procedures for archiving survey-mode data; Don Elliot, Heidi Buck, Pam Lehr, and Annika Green accurately decoded and transcribed thousands of logsheets. The continuous GPS data from southern California and elsewhere made it possible to perform a consistent analysis over the long time covered by these observations. For his pioneering efforts to establish continuous GPS in southern California, for his persistence in maintaining and expanding the network, and for his determination to make all the data, local and global, readily and reliably available through the SOPAC data center, we owe a great deal to the sustained efforts of Yehuda Bock (UCSD). The more recent expansion of the SCIGN network also owes much to the efforts of many other people, including Ken Hudnut and Will Prescott (USGS), Frank Webb (JPL), and John McRaney (USC). Our ability to process data over this wide time span owes much to the early development at MIT of the GAMIT software by Chuck Counselman, Sergei Gourevitch, Yehuda Bock, Rick Abbot, Kurt Feigl, and Mark Murray, and its subsequent improvement by Simon McClusky. Processing was made much easier by the analysis done at SOPAC, in particular by Rosanne Nikolaidis and Matt van Domselaar. We also benefited from the work of Paul Jamason, Michael Scharber, Linette Prawirodirdjo, Brent Gilmore, Jeff Dean, and Chris Roelle, in maintaining the SOPAC data center (UCSD); SOPAC also provided computational resources. In the final step of evaluating the spatial consistency of velocities, we benefited greatly through our interaction with the fault-modeling work of Rob McCaffrey (Portland State University) and Brendan Meade (Harvard). The initial collection of the data used here was funded under many grants and programs, notably by the National Science Foundation, the US Geological Survey, and NASA. The funding for this specific project, and the commitment to making it happen, lie with the Southern California Earthquake Center (SCEC) (of which this is contribution 1500), under support from the NSF and the USGS. We thank the successive Directors (Kei Aki, Dave Jackson, Jean-Bernard Minster, and Tom Jordan) and the rest of the SCEC community, for their support and patience. Dave Jackson was responsible for instigating the idea of the CMM within SCEC, and Ken Hudnut took a lead role in the production of Versions 1 and 2 of the CMM. Z.-K. Shen acknowledges support from USGS grant G11AP20044

\section{References}

Agnew, D. C., S. Owen, Z.-K. Shen, G. Anderson, J. Svarc, H. Johnson, K. E. Austin, and R. Reilinger (2002), Coseismic displacements from the Hector Mine, California, earthquake: Results from survey-mode GPS measurements, Bull. Seismol. Soc. Am., 92, 1355-1364.

Altamimi, Z., P. Sillard, and C. Boucher (2002), ITRF2000: A new release of the International Terrestrial Reference Frame for earth science applications, J. Geophys. Res., 107(B10), 2214, doi:10.1029/2001JB000561.

Anderson, G., D. C. Agnew, and H. O. Johnson (2003), Salton Trough regional deformation estimated from combined trilateration and surveymode GPS data, Bull. Seismol. Soc. Am., 93, 2402-2414.

Argus, D. F., M. B. Heflin, A. Donnellan, F. H. Webb, D. Dong, K. J. Hurst, D. C. Jefferson, G. A. Lyzenga, M. M. Watkins, and J. F. Zumberge (1999), Shortening and thickening of metropolitan Los Angeles measured and inferred by using geodesy, Geology, 27, 703-706.

Argus, D., R. Gordon, M. Heflin, C. Ma, R. Eanes, P. Willis, W. Peltier, and S. Owen (2010), The angular velocities of the plates and the velocity of Earth's centre from space geodesy, Geophys. J. Int., 180, 913-960, doi:10.1111/j.1365-246X.2009.04463.x.

Bawden, G. W., A. Donnellan, L. H. Kellogg, D. N. Dong, and J. Rundle (1997), Geodetic measurements of horizontal strain near the White Wolf fault, Kern County, California, 1926-1993, J. Geophys. Res., 102, 4957-4967.

Becker, T. W., J. L. Hardebeck, and G. Anderson (2005), Constraints on fault slip rates of the southern California plate boundary from GPS velocity and stress inversions, Geophys. J. Int., 160, 634-650, doi:10.1111/ j.1365-246X.2004.02528.x.

Bennett, R. A., R. E. Reilinger, W. Rodi, Y. Li, M. N. Toksoz, and K. Hudnut (1995), Coseismic fault slip associated with the $1992 \mathrm{Mw} 6.1$ Joshua Tree, California, earthquake: Implications for the Joshua Tree-Landers earthquake sequence, J. Geophys. Res., 100, 6443-6461.

Bennett, R. A., W. Rodi, and R. E. Reilinger (1996), Global Positional System constraints on fault slip rates in southern California and northern Baja California, Mexico, J. Geophys. Res., 101, 21,943-21,960.

Blewitt, G., et al. (2005), A Stable North American Reference Frame (SNARF): First Release, Working Group Rep., UNAVCO, Boulder, Colo. (Available at www.unavco.org/research_science/workinggroups_ projects/-snarf/snarf.html.)

Bock, Y., S. A. Gourevitch, C. C. Counselman, R. W. King, and R. I. Abbot (1986), Interferometric analysis of GPS phase observations, Manuscr. Geod., 11, 282-288.

Bock, Y., et al. (1997), Southern California Permanent GPS Geodetic Array: Continuous measurements of crustal deformation between the 1992 Landers and 1994 Northridge earthquakes, J. Geophys. Res., 102, $18,013-18,033$.

Chen, G., and T. A. Herring (1997), Effects of atmospheric azimuth asymmetry on the analysis of space geodetic data, J. Geophys. Res., 102, $20,489-20,502$

Davidson, J. M., and D. W. Trask (1985), Utilization of mobile VLBI for geodetic measurements, IEEE Trans. Geosci. Remote Sens., 23, 426- 437.

Davis, J. L., R. A. Bennett, and B. P. Wernicke (2003), Assessment of GPS velocity accuracy for the Basin and Range Geodetic Network (BARGEN), Geophys. Res. Lett., 30(7), 1411, doi:10.1029/2003GL016961.

Dixon, T. H., M. Miller, F. Farina, H. Wang, and D. Johnson (2000), Present-day motion of the Sierra Nevada block and some tectonic implications for the Basin and Range province, North American Cordillera, Tectonics, 19, 1-24. 
Dong, D. (1993), The horizontal velocity field in southern California from a combination of terrestrial and space-geodetic data, Ph.D. thesis, Mass. Inst. of Technol., Cambridge.

Dong, D., and Y. Bock (1989), Global Positioning System network analysis with phase ambiguity resolution applied to crustal deformation studies in California, J. Geophys. Res., 94, 3949-3965.

Dong, D., T. A. Herring, and R. W. King (1998), Estimating regional deformation from a combination of space and terrestrial geodetic data, J. Geod., 72, 200-214.

Donnellan, A., and G. A. Lyzenga (1998), GPS observations of fault afterslip and upper crustal deformation following the Northridge earthquake, J. Geophys. Res., 103, 21,285-21,298.

Donnellan, A., and F. H. Webb (1998), Geodetic observations of the M5.1 January 29, 1994 Northridge aftershock, Geophys. Res. Lett. $25,667-670$

Donnellan, A., B. H. Hager, R. W. King, and T. A. Herring (1993), Geodetic measurement of deformation in the Ventura basin region, southern California, J. Geophys. Res., 98, 21,727-21,739.

Feigl, K. L., R. W. King, T. A. Herring, and M. Rothacher (1991), A scheme for reducing the effect of Selective Availability on precise geodetic measurements from the Global Positioning System, Geophys. Res. Lett., 18, 1289-1292.

Feigl, K. L., et al. (1993), Space geodetic measurement of crustal deformation in central and southern California, 1984-1992, J. Geophys. Res., 98 21,677-21,712.

Gan, W., J. L. Svarc, J. C. Savage, and W. H. Prescott (2000), Strain accumulation across the Eastern California shear Zone at latitude $36^{\circ} 30^{\prime} \mathrm{N}$, J. Geophys. Res., 105, 16,229-16,236.

Ge, M., G. Gendt, G. Dick, F. Zhang, and C. Reigber (2005), Impact of GPS satellite antenna offsets on scale changes in global network solutions, Geophys. Res. Lett., 32, L06310, doi:10.1029/2004GL022224.

Gonzalez-Garcia, J. J., L. Prawirodirdjo, Y. Bock, and D. Agnew (2003), Guadalupe Island, Mexico as a new constraint for Pacific plate motion, Geophys. Res. Lett., 30(16), 1872, doi:10.1029/2003GL017732.

Gordon, D., C. Ma, and J. W. Ryan (1993), Results from the CDP Mobile VLBI program in the western United States, in Contributions of Space Geodesy to Geodynamics: Crustal Dynamics, Geodyn. Ser. vol. 23, edited by D. E. Smith and D. L. Turcotte, pp. 131-138, AGU, Washington, D. C

Herring, T. (2003), MATLAB Tools for viewing GPS velocities and time series, GPS Solutions, 7, 194-199, doi:10.1007/s10291-003-0068-0.

Herring, T. A., J. L. Davis, and I. I. Shaprio (1990), Geodesy by radio interferometry: The application of Kalman filtering to the analysis of very long baseline interferometry data, J. Geophys. Res., 95, 12,561-12,581.

Herring, T. A., R. W. King, and S. C. McCluskey (2010), Introduction to GAMIT/GLOBK, Version 3.4, 48 pp., Mass. Inst. of Technol. Cambridge.

Hofmann, R. B. (1968), Geodimeter fault measurements in California, Bull. 116-6, Calif. Dep. of Water Resour., Sacramento.

Hudnut, K. W., et al. (1994), Coseismic displacements of the 1992 Landers earthquake sequence, Bull. Seismol. Soc. Am., 84, 625-645.

Hudnut, K. W., et al. (1996), Coseismic displacements of the 1994 Northridge, California, earthquake, Bull. Seismol. Soc. Am., 86, S19-S36.

Jackson, D. D., K. Aki, C. A. Cornell, J. H. Dieterich, T. L. Henyey, M. Mahdyiar, D. Schwartz, and S. N. Ward (1995), Seismic hazards in southern California: Probable earthquakes 1994-2024, Bull. Seismol. Soc. Am., 85, 379-439.

Jackson, D. D., Z.-K. Shen, D. Potter, X. Ge, and L.-Y. Sung (1997), Earthquakes and strain in southern California, Science, 277, 1621-1622.

Ji, C., D. J. Wald, and D. V. Helmberger (2002), Source description of the 1999 Hector Mine, California, earthquake, part I: Wavelet domain inversion theory and resolution analysis, Bull. Seismol. Soc. Am., 92, 1192-1207.

Ji, C., K. M. Larson, Y. Tan, K. W. Hudnut, and K. Choi (2004), Slip history of the 2003 San Simeon earthquake constrained by combining 1-Hz GPS, strong motion, and teleseismic data, Geophys. Res. Lett., 31, L17608, doi:10.1029/2004GL020448.

Johnson, H., and D. Agnew (1995), Monument motion and measurements of crustal velocities, Geophys. Res. Lett., 22, 2905-2908.

Johnson, H., F. Wyatt, and D. C. Agnew (1994), Present-day crustal deformation in southern California, J. Geophys. Res., 99, 23,951-23,974.

King, N. E., and J. C. Savage (1983), Strain-rate profile across the Elsinore, San Jacinto, and San Andreas faults near Palm Springs, California, 1973-1981, Geophys. Res. Lett., 10, 55-57.

King, N. E., and J. C. Savage (1984), Regional deformation near Palmdale, California, 1973-1983, J. Geophys. Res., 89, 2471-2477.

King, N. E., P. Segall, and W. Prescott (1987), Geodetic measurements near Parkfield, California, 1959-1984, J. Geophys. Res., 92, 2747-2766.
King, N. E., et al. (2007), Space geodetic observation of expansion of the San Gabriel Valley, California, aquifer system, during heavy rainfall in winter 2004-2005, J. Geophys. Res., 112, B03409, doi:10.1029/ 2006JB004448.

Larsen, S., and R. Reilinger (1992), Global Positioning System Measurements of strain accumulation across the Imperial Valley, California: 1986-1989, J. Geophys. Res, 97, 8865-8876.

Larson, K. M., and D. C. Agnew (1991), Application of the Global Positioning System to crustal deformation measurement: 1. Precision and accuracy, J. Geophys. Res., 96, 16,547-16,565.

Larson, K. M., and F. H. Webb (1992), Deformation in the Santa Barbara Channel from GPS measurements 1987-1991, Geophys. Res. Lett., 19, 1491-1494.

Lisowski, M., J. C. Savage, and W. H. Prescott (1991), The velocity field along the San Andreas fault in central and southern California, J. Geophys. Res., 96, 8369-8389.

Ma, X. Q., and N. J. Kusznir (1994), Effects of rigidity layering, gravity and stress relaxation on 3-D subsurface fault displacement fields, Geophys. J. Int., 118, 201-220.

McCaffrey, R. (2005), Block kinematics of the Pacific/North America plate boundary in the southwestern United States from inversion of GPS, seismological, and geologic data, J. Geophys. Res., 110, B07401, doi:10.1029/2004JB003307.

McCaffrey, R., A. I. Qamar, R. W. King, R. Wells, G. Khazaradze C. A. Williams, C. W. Stevens, J. J. Vollick, and P. C. Zwick (2007), Fault locking, block rotation and crustal deformation in the Pacific Northwest, Geophys. J. Int., 169, 1315-1340, doi:10.1111/j.1365246X.2007.03371.x.

McCarthy, D. D. (1992), IERS Standards, Tech. Note 13, Obs. de Paris, Paris.

McClusky, S., et al. (2000), Global Positioning System constraints on plate kinematics and dynamics in the eastern Mediterranean and Caucasus, J. Geophys. Res., 105, 5695-5719.

McClusky, S. C., S. C. Bjornstad, B. H. Hager, R. W. King, B. J. Meade, M. M. Miller, F. C. Monastero, and B. J. Souter (2001), Present day kinematics of the Eastern California Shear Zone from a geodetically constrained block model, Geophys. Res. Lett., 28, 3339-3372.

McKenzie, D., and R. L. Parker (1967), The North Pacific: An example of tectonics on a sphere, Nature, 216, 1276-1280.

Meade, B., and B. H. Hager (2005a), Spatial localization of moment deficits in southern California, J. Geophys. Res., 110, B04402, doi:10.1029/ 2004JB003331.

Meade, B. J., and B. H. Hager (2005b), Block models of crustal motion in southern California constrained by GPS measurements, J. Geophys. Res., 110, B03403, doi:10.1029/2004JB003209.

Miller, M. M., D. P. Johnson, T. H. Dixon, and R. K. Dokka (2001), Refined kinematics of the Eastern California Shear Zone from GPS observations, 1993-1998, J. Geophys. Res., 106, 2245-2263.

Minster, J. B., and T. H. Jordan (1987), Vector constraints on western U. S. deformation from space geodesy, neotectonics, and plate motions, J. Geophys. Res., 92, 4798-4804.

Murray, J., and J. Langbein (2006), Slip on the San Andreas fault at Parkfield, California, over two earthquake cycles, and the implications for seismic hazard, Bull. Seismol. Soc. Am., 96, S283-S303.

Niell, A. E. (1996), Global mapping functions for the atmospheric delay of radio wavelengths, J. Geophys. Res., 101, 3227-3246.

Nikolaidis, R. M. (2002), Observation of global and seismic deformation with the Global Positioning System, Ph.D. thesis, Univ. of Calif., San Diego, La Jolla.

Owen, S., G. Anderson, D. C. Agnew, H. Johnson, K. Hurst, R. Reilinger, Z.-K. Shen, J. Svarc, and T. Baker (2002), Early postseismic displacements from the M-1exW 7.1 Hector Mine earthquake as measured by survey-mode GPS, Bull. Seismol. Soc. Am., 92, 1423-1432.

Parks, W., and T. Dial (1997), Using GPS to measure leveling section height difference in a ground subsidence area in Imperial Valley, California, Surv. Land Inf. Syst., 57, 100-119.

Parsons, T. (2006), Tectonic stressing in California modeled from GPS observations, J. Geophys. Res., 111, B03407, doi:10.1029/ 2005JB003946.

Plattner, C., R. Malservisi, T. H. Dixon, P. LaFemina, G. F. Sella, J. Fletcher, and F. Suarez-Vidal (2007), New constraints on relative motion between the Pacific Plate and Baja California microplate (Mexico) from GPS measurements, Geophys. J. Int., 170, 1373-1380, doi:10.1111/ j.1365-246X.2007.03494.x.

Pollitz, F. F., G. Peltzer, and R. Burgmann (2000), Mobility of continental mantle: Evidence from postseismic geodetic observations following the 1992 Landers earthquake, J. Geophys. Res., 105, 8035-8054.

Reilinger, R., et al. (2006), GPS constraints on continental deformation in the Africa-Arabia-Eurasia continental collision zone and implications for 
the dynamics of plate interactions, J. Geophys. Res., 111, B05411, doi:10.1029/2005JB004051

Rolandone, F., D. Dreger, M. Murray, and R. Burgmann (2006), Coseismic slip distribution of the $2003 \mathrm{M}_{w}$ 6.6 San Simeon earthquake, California, determined from GPS measurements and seismic waveform data, Geophys. Res. Lett., 33, L16315, doi:10.1029/2006GL027079.

Rolandone, F., R. Burgmann, D. C. Agnew, I. A. Johanson, D. C. Templeton, M. A. d'Alessio, S. J. Titus, C. DeMets, and B. Tikoff (2008), Aseismic slip and fault-normal strain along the central creeping section of the San Andreas fault, Geophys. Res. Lett., 35, L14305, doi:10.1029/ 2008 GL034437.

Saastamoinen, J. (1972), Atmospheric correction for the troposphere and stratospphere in radio ranging to satellites, in The Use of Artificial Satellites for Geodesy, Geophys. Monogr. Ser., vol. 15 edited by S. W. Henrikson, A. Mancini, and B. H. Chovitz, pp. 247-251, AGU, Washington, D. C. Saucier, F., and E. Humphreys (1993), Horizontal crustal deformation in southern California from joint models of geologic and very long baseline interferometry measurements, in Contributions of Space Geodesy to Geodynamics: Crustal Dynamics, Geodyn. Ser., vol. 23, edited by D. E. Smith and D. L. Turcotte, pp. 138-176, AGU, Washington, D. C.

Savage, J. C. (1975), A possible bias in the California state Geodimeter data, J. Geophys. Res., 80, 4078-4088.

Savage, J. C. (1983), Strain accumulation in western United States, Annu. Rev. Earth Planet. Sci., 11, 11-43.

Savage, J. C., and M. Lisowski (1995a), Interseismic deformation along the San Andreas fault in southern California, J. Geophys. Res., 100, 12,70312,717 .

Savage, J. C., and M. Lisowski (1995b), Changes in long-term extension rates associated with the Morgan Hill and Loma Prieta earthquakes in California, Geophys. Res. Lett., 22, 759-762.

Savage, J. C., and M. Lisowski (1998), Viscoelastic coupling model of the San Andreas fault along the big bend, southern California, J. Geophys. Res., 103, 7281-7292.

Savage, J. C., and W. H. Prescott (1973), Precision of Geodolite distance measurements for determining fault movement, J. Geophys. Res., 78 , 6001-6008.

Savage, J. C., and J. L. Svarc (1997), Postseismic deformation associated with the $1992 \mathrm{M}_{w} 7.3$ Landers earthquake, Southern California, J. Geophys. Res., 102, 7565-7577.

Savage, J. C., W. H. Prescott, and G. Gu (1986), Strain accumulation in southern California, 1973-1984, J. Geophys. Res., 91, 7455-7473.

Savage, J. C., M. Lisowski, and W. H. Prescott (1996), Observed discrepancy between Geodolite and GPS distance measurements, J. Geophys. Res., 101, 25,547-25,552.

Savage, J. C., J. L. Svarc, and W. H. Prescott (2003), Near-field postseismic deformation associated with the 1992 Landers and 1999 Hecto Mine, California, earthquakes, J. Geophys. Res., 108(B9), 2432, doi:10.1029/2002JB002330.

Savage, J. C., J. L. Svarc, and W. H. Prescott (2004), Interseismic strain and rotation rates in the northeast Mojave domain, eastern California, J. Geophys. Res., 109, B02406, doi:10.1029/2003JB002705.

Schaffrin, B., and Y. Bock (1988), A unified scheme for processing GPS dual-band phase observations, J. Geod., 62, 142-160, doi:10.1007/ BF02519222.

Schmalzle, G., T. H. Dixon, R. Malservisi, and R. Govers (2006), Strain accumulation across the Carrizo segment of the San Andreas Fault, California: Impact of laterally varying crustal properties, J. Geophys. Res., 111, B05403, doi:10.1029/2005JB003843.

Segall, P., and R. Harris (1987), Earthquake deformation cycle on the San Andreas fault near Parkfield, California, J. Geophys. Res., 92, $10,511-10,525$

Shen, Z.-K., and D. D. Jackson (1993), GPS reoccupation of early triangulation sites: Tectonic deformation of the Southern Coast Ranges, J. Geophys. Res., 98, 9931-9946.
Shen, Z.-K., D. Jackson, Y. Feng, M. Cline, M. Kim, P. Fang, and Y. Bock (1994), Postseismic deformation following Landers earthquake, California, June 28, 1992, Bull. Seismol. Soc. Am., 94, 780-791.

Shen, Z.-K., D. D. Jackson, and X. B. Ge (1996), Crustal deformation across and beyond the Los Angeles basin from geodetic measurements, J. Geophys. Res., 101, 27,957-27,980.

Shen, Z.-K., D. D. Jackson, and Y. Y. Kagan (2007), Implications of geodetic strain rate for future earthquakes, with a five-year forecast of M5 earthquakes in southern California, Seismol. Res. Lett., 78, 117-120.

Shen-Tu, B. M., W. E. Holt, and A. J. Haines (1999), Deformation kinematics in the western United States determined from Quaternary fault slip rates and recent geodetic data, J. Geophys. Res., 104, 28,927-28,955.

Spinler, J., R. Bennett, M. Anderson, S. McGill, S. Hreinsdottir, and A. McCallister (2010), Present-day strain accumulation and slip rates associated with southern San Andreas and eastern California shear zone faults, J. Geophys. Res., 115, B11407, doi:10.1029/2010JB007424.

Springer, T. A., G. Beutler, and M. Rothacher (1999), Improving the orbit estimates of GPS satellites, J. Geod., 73, 147-157.

Wald, D. J., T. H. Heaton, and K. W. Hudnut (1996), The slip history of the 1994 Northridge, California, earthquake determined from strongmotion, teleseismic, GPS, and leveling data, Bull. Seismol. Soc. Am., 86, S49-S70.

Walls, C., T. Rockwell, K. Mueller, Y. Bock, S. Williams, J. Pfanner, J. Dolan, and P. Fang (1998), Escape tectonics in the Los Angeles metropolitan region and implications for seismic risk, Nature, 394, 356-360.

Ward, S. N. (2007), Methods for evaluating earthquake potential and likelihood in and around California, Seismol. Res. Lett., 78, 121-133.

Wdowinski, S., Y. Sudman, and Y. Bock (2001), Geodetic detection of active faults in Southern California, Geophys. Res. Lett., 28, 2321-2324.

Wdowinski, S., B. Smith-Konter, Y. Bock, and D. Sandwell (2007), Diffuse interseismic deformation across the Pacific-North America plate boundary, Geology, 35, 311-314.

Wernicke, B. P., A. M. Friedrich, N. A. Niemi, R. A. Bennett, and J. L. Davis (2000), Dynamics of plate boundary fault systems from Basin and Range Geodetic Network (BARGEN) and geologic data, GSA Today, 10, 1-3.

Williams, S. D. P., Y. Bock, P. Fang, P. Jamason, R. M. Nikolaidis, L. Prawirodirdjo, M. Miller, and D. J. Johnson (2004), Error analysis of continuous GPS position time series, J. Geophys. Res., 109 B03412, doi:10.1029/2003JB002741.

Zhu, S., F. Massmann, Y. Yu, and C. Reigber (2003), Satellite antenna phase center offsets and scale errors in GPS solutions, J. Geod., 76 , 668-672, doi:10.1007/s00190-002-0294-1.

D. C. Agnew and P. Fang, Institute of Geophysics and Planetary Physics, Scripps Institution of Oceanography, University of California, San Diego, La Jolla, CA 92093-0225, USA. (dagnew@ucsd.edu; pfang@ucsd.edu)

D. Dong, Jet Propulsion Laboratory, California Institute of Technology, MS 238-600, 4800 Oak Grove Dr., Pasadena, CA 91109, USA. (danan. dong@jpl.nasa.gov)

T. Herring and R. W. King, Department of Earth, Atmospheric and Planetary Sciences, Massachusetts Institute of Technology, 77 Massachusetts Ave., Cambridge, MA 02139-4307, USA. (tah@mit.edu; rwk@mit.edu)

Z.-K. Shen, Department of Earth and Space Sciences, University of California, 595 Charles E Young Dr., Los Angeles, CA 90095-1567, USA. (zshen@ucla.edu)

M. Wang, State Key Laboratory of Earthquake Dynamics, Institute of Geology, China Earthquake Administration, PO Box 9803, Beijing 100029, China. (mwang@gps.gov.cn) 